\title{
EL FORMENT A LA BARCELONA BAIXMEDIEVAL: PREUS, MESURES I FISCALITAT (1283-1345) '
}

\author{
PERE ORTÍ I GOST
}

\begin{abstract}
SUMARI
1. Les fonts: 1.1. Els llibres de comptes dels molins reials de Barcelona i del batlle general de Catalunya.- 1.2. Els llibres de comptes de la Pia Almoina de Barcelona.- 2. Les mesures.- 3. Els impostos sobre la compra-venda de forment.4. «Portar, porgar, moldre i coure».- 5. Evolució del preu del forment: 5.1. Moviments interanuals.- 5.2. Moviments generals.- 6. Conclusions.
\end{abstract}

La difusió a Catalunya des de finals del segle XIII de la comptabilitat senyorial ens ha deixat, com a la resta de l'Europa occidental, un conjunt de llibres de comptes que permeten estudis quantitatius més o menys precisos. El principal problema d'aquestes fonts, sobretot al principi del segle XIV, és la manca d'una certa continuïtat; això ens impedeix d'elaborar sèries suficientment llargues perquè puguin ser tractades amb el mínim rigor $\mathrm{i}$ aportin dades significatives. Però, malgrat totes aquestes limitacions, qualsevol informació de tipus quantitatiu, per petita que sigui, ens serà vàlida sempre que es consideri com una simple tècnica d'anàlisi i no es converteixi en l'objecte historiogràfic per antonomàsia ${ }^{2}$. Així, per exemple, els llibres de comptes dels

' Abreviatures emprades en el present treball: ACA, Arxiu de la Corona d'Aragó; $A C B$, Arxiu Capitular de Barcelona; AHCB, Arxiu Històric de la ciutat de Barcelona.

Així mateix, volem agrair les indicacions dels Drs. Gaspar Feliu i Monfort, Antoni Riera i Melis i Manuel Sánchez Martínez.

2 Com ho assenyala Guy Bois: "Les objections (als mètodes quantitatius) d'ordre pratique ont, à première vue, plus de consistance. Légitimes pour le traitement des sources de l'époque moderne ou contemporaine, ces méthodes deviendraient un faux-semblant dans l'étude d'un passé plus reculé. Comme il est aisé, en effet, de broder sur ce thème en plongeant dans les délices de l'hypercritique! Et d'ironiser sur les bévues d'un historien 
molins reials de Barcelona, del batlle general de Catalunya o de la Pia Almoina de la ciutat comtal ofereixen diverses notícies de tipus quantitatiu sobre la vida econòmica de la ciutat, com poden ser múltiples referències als preus de diversos productes, a salaris, etc. que permeten seguir la seva evolució durant la primera meitat del segle XIV.

En aquest cas ens centrarem en l'estudi dels preus del forment, ingredient bàsic del règim alimentari de les societats medievals. Prèviament ens caldrà analitzar el valor de les mesures barcelonines $i$, per poder valorar el cost real del $\mathrm{pa}$, haurem de conèixer, en primer lloc, els preus dels diferents processos industrials que porten del forment al pa $\mathrm{i}$, seguidament, el conjunt d'impostos que gravaven la comercialització dels cereals. A través de l'estudi de l'evolució dels preus, intentarem realitzar una primera aproximació al comportament del mercat de cereals barceloní durant l'etapa inicial de la crisi baixmedieval, concretament entre 1283 i 1345 , contrastant-ho amb els treballs fets a partir de fonts no quantitatives. Finalment, compararem els nostres resultats amb alguns estudis referents a la Corona d'Aragó i al món mediterrani, amb la intenció de precisar una mica més la cronologia de les crisis de subsistències.

\section{LES FONTS}

Per a aquest treball hem utilitzat dos tipus de fonts diferents: per una banda, la informació sobre els preus del forment que aporten els llibres de comptes dels molins reials de Barcelona i els resums d'aquests que apareixen en els llibres de comptes del batlle general de Catalunya; i, per l'altra, hem estudiat també les compres de forment realitzades per la Pia Almoina de la Seu de Barcelona, institució dedicada a l'alimentació dels pobres. La informació i el caràcter mateix d'ambdues fonts és molt diferent; per això caldrà, en primer lloc, contextualitzar les dades que ens aporten per poder-les contrastar.

\subsection{Els llibres de comptes dels molins reials de Barcelona i del batlle general de Catalunya}

\footnotetext{
comparant les prix de deux boisseaux de froment sans s'être assuré que leur qualité était strictement identique! Attitude stérile et dérisoire. Même grossière et approximative, l'élaboration quantitative (à condition de ne pas en "sacraliser» les résultats) est préférable à l'absence de tout traitement statistique. Celui qui s'y refuse, se réfugie en réalité dans un sous-quantitatif qui ne s'avoue point et s'expose, du même coup, à des erreurs d'une autre ampleur» (Guy BoIs, Crise du feodalisme, París, 1976, p.19).
} 
La renda dels molins del Rec Comtal de Barcelona era la principal del patrimoni reial de la ciutat. La gestió d'aquesta renda comportava la confecció de diversos llibres de comptes alguns dels quals ens informen del preu del forment. Això és degut al fet que determinats pagaments assignats als molins anaven fixats en forment; però, com que al segle XIV es pagaven en diners, era necessari saber el preu diari del forment i per justificar aquestes despeses calia anotar-les en el llibre de comptes .

Una de les millors fonts per a l'estudi dels preus del forment de Barcelona són dos del quatre llibres de comptes que generava anualment la gestió dels molins reials de la ciutat comtal ${ }^{4}$ : concretament, el llibre que hem anomenat «de sortides» i el llibre del Clot Sobirà. En aquests, apareix indicat diàriament el preu d'un quartà de forment a la mesura dels molins, ja que s'havien de pagar les mulneries fixades en aquesta quantitat'. Malauradament, d'aquests llibres només se'n conserven els corresponents als anys 1336 i $1339^{\circ}$. Proporcionen també una dada complementària molt interessant: aquells salaris d'oficials reials dels molins i els violaris assignats a les seves rendes i a les de la Farneria, que estaven fixats en una quantitat de forment diària, es pagaven realment segons el preu diari. Aquests pagaments eren d'un o dos quartans, algunes vegades mòlts $i$ unes altres no. Així, el valor anual d'aquests violaris i/o salaris, que apareixen en els llibres de comptes del batlle general de Catalunya, ens permet obtenir el preu mitjà anual del forment. Encara que aquests violaris es concediren fonamentalment a principis del segle XIV, tingueren una llarga durada, ja que, un cop finits, foren assignats a la testamentaria de Jaume II i això va fer que s'anessin pagant fins a mitjan segle XIV ${ }^{7}$. Existeixen també dos

3 Vegeu: Pere ORTi Gost, Els molins reials del Rec Comtal de Barcelona durant la primera meitat del segle XIV, tesi de llicenciatura inèdita, Barcelona 1991.

${ }^{4}$ La comptabilitat comuna dels casals de Sant Pere, del Soler, dels Molins Nous, del Clot Jussà i del Molí Carbonell es portava en dos llibres diferents: un on es registraven els ingressos (que anomenarem «llibres de les entrades») i un altre on es calculaven els beneficis reials $\mathrm{i}$ s'anotaven les despeses assignades a aquests beneficis («llibre de les sortides»). Els altres dos llibres corresponien un als cinc casals anomenats de Bonanat Sapera i l'altra al casal del Clot Sobirà, tots ells construïts al segle XIV (ibidem, pp.117-130).

s Una antiga manera de remunerar el moliner era donant-li una quantitat de forment diària o una part de les rendes del molí que s'anomenava «mulneria». A Barcelona s'establiren contractes d'aquest tipus cedint la quantitat de forment a perpetuitat i com que els ingressos dels molins estaven monetitzats s'havien de pagar les mulneries segons el preu del forment (ibidem, pp.32-40).

" Ambdós són «llibres de sortides» (ACA, Reial Patrimoni, Batllia, Classe VIII, G, núm. 3 i 4). Existeix un llibre de comptes del casal del Clot Sobirà on també hi ha pagaments de mulneria, però està sense datar encara que probablement sigui de 1349 (ACA, Batllia, Cl. VIII, G, núm. 2).

7 Ibidem, pp.184-186. 
capbreus de les rendes reials de Catalunya, un de $1315^{\circ} \mathrm{i}$ un altre de $1327^{\circ}$, on apareix una aproximació al valor d'aquests violaris. Finalment, en els llibres de comptes dels molins que hem anomenat "de les entrades» s'anotava el pagament mensual del salari de l'escrivà, que era d'un quartà de forment diari ${ }^{10}$. Per tant, els anys que s'ha conservat aquest tipus de llibre podem saber el preu mitjà mensual del forment ".

En resum, els llibres de comptes dels molins ens ofereixen el preu diari del forment durant els anys 1336 i 1339 i el preu mensual dels anys 1334 i 1335 ; i els del batlle general de Catalunya, el preu mitjà anual dels anys 1286, 1288, $1301,1318,1322,1326$ i dels compresos entre 1329 i 1337 i entre 1339 i $1342^{12}$.

No tenim cap tipus d'informació sobre com es calculava el preu del forment; només que es feia seguint el preu de Barcelona. Sabem que a la ciutat aquest preu era lliure i solament en ocasions de crisi excepcional el Consell de la ciutat el regulà, encara que, per als anys estudiats, aquest només intervingué el preu de la farina o de l'ordi i prohibí que s'apugés el preu més d'un cop al dia ${ }^{13}$. A més, els preus que s'observen per a l'any 1334 ens mostren unes variacions que no poden respondre a un preu intervingut.

Finalment, a través dels llibres de comptes dels molins es pot seguir l'evolució del consum de cereals a la ciutat a partir dels seus ingressos. Malauradament, això només és possible per als anys 1334, 1335, 1336 i $1339^{14}$, ja que, en aquest cas, només ens serveixen els llibres de comptes dels molins. Les dades més globals que apareixen en el llibre del batlle general de Catalunya, com el preu de l'arrendament del conjunt dels

${ }^{8}$ Manuel de Bofarull y De SARTorio, Rentas de la Antigua Corona de Aragón, "CoDoIn ACA», XXXIX, Barcelona, 1889, pp.68-72.

9 Ibidem, pp.30-33.

10 P. ORTI, op. cit., pp.176-177. L'escrivà dels molins era el funcionari encarregat, entre altres tasques, de la confecció dels llibres de comptes.

"D'aquests llibres només es conserven els corresponents als anys 1335 (ACA, Batllia, Cl. VIII, G, núm. 1) i 1334 (ídem, núm. 34; existeixen alguns fragments d'aquest compte als núm. 2 i 33 ).

12 ACA, Reial Patrimoni, Mestre Racional, reg. del 966 al 969 i del 972 al 986.

13 Aquestes dues ordinacions només s'aplicaren durant les crisis més fortes: $1325 \mathrm{i}$ 1332-34 (vegeu: F. ROCA, La regulación de la vida cotidiana por el municipio de Barcelona (1300-1350), tesi doctoral inèdita, Barcelona, 1975, II, pp.816-818). En general, la política de la ciutat es centrà més en controlar la revenda, les mesures, la qualitat i les mescles de blat (vegeu ibidem, II, pp.775-846); el mateix tipus d'actuació es veu, per exemple, a Tortosa (Albert CURTO I HOMEDES, La intervenció municipal en l'abastament d'una ciutat catalana: Tortosa, segle XIV, Barcelona, 1988, pp.53-68).

14 Vegeu notes 6 i 11. 
molins reials o el pagament de certes parts de molins alienats, $s$ 'han de prendre amb molt de compte i només es poden considerar d'una manera aproximativa ${ }^{1 s}$.

\subsection{Els llibres de comptes de la Pia Almoina de Barcelona}

Una altra font seriada que ens permet conèixer el preu del forment són els llibres de comptes de la Pia Almoina de la Seu de Barcelona. Aquesta institució, dedicada a l'alimentació dels pobres de la ciutat, fou creada a partir de diferents donacions d'almoines realitzades d'ençà del 1161. Aquestes fundacions caritatives eren gestionades pels canonges de la catedral o per beneficiats establerts pels mateixos instituidors. Durant el segle XIII, a mesura que augmentaren les fundacions s'inicià un procés de concentració de la gestió d'aquestes en mans del capítol, procés que s'accentuà durant la dècada dels $60 \mathrm{i}$ que finalitzà el 1275 quan realment es creà la Pia Almoina com a institució amb personalitat jurídica i patrimoni propi. Continuà lligada al capítol, però aquest només nomenava dos canonges encarregats de representar $\mathrm{i}$ administrar els béns de la Pia Almoina i de realitzar la seva funció: donar menjar un cop al dia als pobres ". Aquests procuradors havien de confeccionar uns llibres de comptes per a registrar la seva gestió, que eren fiscalitzats per dos canonges nomenats expressament pel bisbe i pel capítol. Aquest càrrec era de duració biennal i el canvi de procuradors es realitzava en teoria per Santa Creu de maig ${ }^{17}$.

Per tant, els llibres de comptes cobreixen la gestió de la Pia Almoina durant dos anys començant a principis de maig $\mathrm{i}$ acabant a finals d'abril.

is Així, per exemple, el preu de l'arrendament dels molins sofrí una baixada espectacular l'any 1327, que s'explica simplement per un canvi en el sistema de càlcul d'aquest preu (P. ORTI, op. cit., pp.182-189).

${ }_{16}$ Vegeu Josep BAUCells I Reig, La Pia Almoina de la Seo de Barcelona. Origen y desarrollo, «A pobreza e a assistênçia aos pobres na Península Ibérica durante a Idade Média. Actas das 1.as jornadas luso-espanholas de História Medieval», Lisboa, 1974, pp. 73-135; ídem, Gènesi de la Pia Almoina de la Seu de Barcelona: els fundadors, «La pobreza y la asistencia a los pobres en la Catalunya medieval», Barcelona, 1980, pp. 17-75; ídem, El Baix LLobregat i la Pia Almoina de la Seu de Barcelona, Barcelona, 1984.

17 Segons la normativa de 1275 (J. BAUCElls, La Pia Almoina de la Seo de Barcelona, pp.115-117). Si ens fixem en els llibres de comptes, veurem que no es complia exactament: fins al 1317, a excepció del període comprès entre 1293 i 1296, normalment es realitzava el canvi durant els primers dies del mes de maig; a partir del 1317 i de manera sistemàtica, es realitzà l'1 de maig. 
D'aquests llibres es conserva pràcticament la sèrie completa entre $1283 \mathrm{i}$ $1345^{18}$. Tipològicament no són tots iguals: fins a l'any 1316 , en un mateix volum s'agrupen les rebudes $\mathrm{i}$ dates dels dos anys ${ }^{19}$; entre 1317 i 1330, es confeccionen dos llibres, un per a les rebudes i un altre per a les dates ${ }^{20}$; entre 1331 i 1336 es continuen fent dos llibres per separat però, a més, tant algunes rebudes com algunes despeses s'anoten per menut en uns altres dos llibres, dades que apareixen resumides en el primer ${ }^{21}$; finalment, a partir del 1337 es torna a utilitzar un sol llibre major per a rebudes i dates, però es mantingueren els llibres per menut d'algunes rebudes ${ }^{22}$. Aquests canvis estaven motivats per una millora dels sistemes de comptabilitat i per l'augment de les rendes de la Pia Almoina.

Aquests llibres són la millor font barcelonina per a l'estudi de la gestió d'un patrimoni senyorial, no tan sols pel període que cobreixen (com hem vist, hi ha un important nombre de llibres ja del final del segle XIII) sinó, sobretot, per la qualitat de la informació: apareixen detallades totes les rendes, tant urbanes com rurals, com es perceben, els conflictes que generava la seva percepció, l'evolució i destinació de les rendes en espècie, etc., i tot això no tan sols a Barcelona i el seu territori sinó en altres zones com al Baix Llobregat, Maresme, Penedès, etc. Però aquesta font ens és útil també per a uns altres camps, des de l'alimentació a la història econòmica. Des d'aquest últim punt de vista, apareixen preus del forment, llegums, carn, vi, oli, llenya, dels béns

${ }_{18}$ ACB, Pia Almoina, B, Administració, Sortides, format major. Aquesta part de l'Arxiu resta pendent de classificació definitiva; d'ara endavant $A C B$, PA- més l'any en què comença indicant, quan sigui el cas, si sols és de rebudes (R) o dates (D).

${ }^{19}$ D'aquest primer període es conserva el corresponent als anys 1283 i $1284 \mathrm{i}$ la sèrie completa entre 1288 i 1316 . Un exemple d'aquest tipus el podem trobar en l'estudi i la transcripció del compte corresponent a l'any 1284: María ECHÁNIZ SANS, La alimentación de los pobres asistidos por la Pia Almoina de la catedral de Barcelona según el libro de cuentas de 1283-84, dins Alimentació i societat a la Catalunya medieval, "Anuario de Estudios medievales», annex 20, Barcelona, 1988, pp.173-261

20 De llibres de rebudes es conserven els dels anys 1319-20, 1323-24, 1325-26, 1327-28 i 1329-30 i, de les dates, tots els compresos entre 1317 i 1326 i el de 132930.

${ }^{21}$ D'aquest període es conserven tots els llibres majors, però dels comptes per menut només hi ha el de rebudes del 1334 i els de dates dels anys 1334 i 1335 . Els llibres per menut són anuals. Sobre l'estructura de les despeses dels llibres majors, vegeu: Tomàs LóPEZ PIZCUETA La alimentación de los pobres de la Pia Almoina de Barcelona durante el «mal any primer», "ler col·loqui d'història de l'alimentació a la Corona d'Aragó», Lleida, 1990, en premsa.

${ }^{22}$ D'aquesta època es conserven els corresponents als anys compresos entre $1337 \mathrm{i}$ 1342, a més del de l'any 1345-46. De la resta del segle XIV pràcticament no en queda res: dos del final de la dècada dels 50 i un de dates de 1388 a 1390. 
immobles a través de la important quantitat de lluïsmes que anualment rebia, salaris d'obrers, de mestres d'obres, etc.

Centrant-nos en el tema que ens interessa, la informació sobre el forment és abundant, ja que la Pia Almoina feia compres regularment, però no és homogènia. En primer lloc, és difícil datar les compres: en els primers llibres apareixen barrejades entre la majoria de les despeses ordenades cronològicament, la qual cosa ens permet datar-les aproximadament ${ }^{23}$; però, a partir del 1297 , les compres de forment es separen de la resta de les despeses i no van datades fins el 1337. Com ja hem assenyalat, l'any comptable d'aquests llibres començava el maig; per tant, les mitjanes anuals calculades a partir d'aquests llibres es faran sobre un any entre maig i abril, cosa que dificulta la comparació amb les mitjanes fetes a partir de les dades dels molins reials de Barcelona que, com hem vist, reflecteixen l'any de gener a desembre.

Apareix també informació sobre els venedors: les primeres mencions, del 1319 , són encara esporàdiques $\mathrm{i}$ incompletes, però progressivament seran més riques, fins a arribar al període 1337 a 1345 quan s'indica sempre el nom, origen $\mathrm{i}$ ofici del venedor; fins $\mathrm{i}$ tot, quan aquest és un simple intermediari, s'anota també de qui ho és.

A diferència de la informació subministrada pels molins de Barcelona, que ens permeten calcular mitjanes anuals i mensuals sobre el preu diari del forment, les dades de la Pia Almoina només ens ofereixen un conjunt de preus de l'any que reflecteixen, més o menys el preu mitjà anual segons el nombre de compres i el seu repartiment al llarg de l'any, sempre que les puguem datar. Per poder calibrar la informació desigual que ens aporten aquests llibres de comptes cal endinsar-se una mica dins la lògica interna de l'aprovisionament i del consum de forment de la Pia Almoina, encara que per això ens haguem de desviar una mica del tema central d'aquest treball. Ens caldrà saber quins tipus de blat consumia, d'on el rebia, quines quantitats comprava $\mathrm{i}$ consumia, a qui les comprava $\mathrm{i}$ com evolucionà tot això en els 62 anys estudiats.

La Pia Almoina sempre comprà forment per a la confecció del seu pa $\mathrm{i}$ mai no utilitzà altres tipus de gra tot i rebre de les seves rendes censos en ordi. Normalment, aquest ordi era venut en els llocs on es produïa. Fins i tot, l'any 1334, quan, en plena crisi de subsistència, el procurador de la Pia Almoina hagué recollit, amb grans dificultats, els censos en espècies de Vilafranca del Penedès, llogà una botiga per vendre l'ordi i comprar més forment que envià a Sitges per a ser embarcat cap a Barcelona ${ }^{24}$; o, el mateix

${ }^{23}$ El llibre dels anys 1295 i 1296 és una excepció, ja que apareixen exactament datades.

${ }^{24}$ ACB, PIA-1333R f.115r-117r. 
any, de les rendes en mestall, es trià el forment que contenia i se'n va vendre la resta ${ }^{25}$. Aquestes notícies demostren un cop més «la resistència d'àmplies capes de la societat a enfosquir, fins $\mathrm{i}$ tot, en èpoques d'emergència, llur pa»" ${ }^{26}$.

Existien a l'edat mitjana diferents tipus de forment. Normalment, la Pia Almoina comprava el forment comú, encara que també es troben altres tipus com forment de «sexa» o xeixa i de "moltís». El primer sembla més apreciat ${ }^{27} \mathrm{i}$ el segon no l'hem pogut identificar. Malgrat que puguin ser forments de major qualitat, quan apareixen no s'observa que tinguin un preu major; podria ser que, quan la Pia Almoina compra aquest tipus de blat, és perquè no n'hi ha d'altre o la diferència de preu és mínima. A vegades també es distingeix el forment segons la seva procedència indicant que provenen de Sicilia; Sardenya, Aragó o Empordà.

Les necessitats de forment de la Pia Almoina anaren creixent progressivament dins el període que analitzem, però hi ha un salt important entre $1311 \mathrm{i}$ 1315. Per tant, com es pot veure en el gràfic 1 , es poden establir dues etapes separades per l'any 1313: d'unes necessitats d'unes 400 q. de farina de mitjana es passà a un consum anual al voltant de les $800 \mathrm{q}$. El perquè d'aquest canvi queda fora dels límits d'aquest treball, però té una gran importància per a la lectura dels preus que hi apareixen.

2) ACB, PA-1334 (menut) s/n. A partir d'aquesta dada tenim un exemple de la composició del mestall: de les 104 q. 10,5 qà. (en mesura d'ordi de Barcelona) «d'aquest mestay exiren XXII quarteres d'espelta neta les quals es van vendre a diversos preus, CXII s.; item, exiren $\mathrm{X}$ de porgadures de les quals se trià alguna espelta e ordi que done a civada algunes vegades" i 72 q. 10,5 qà. de forment. Això representa 69,5\% de forment, $21 \%$ d'espelta i $9,5 \%$ de porgadures. Per tant, dóna una proporció aproximada de $2 / 3$ que era la més comuna (Louis STOUFF, Ravitaillement et alimentation en Provence aux XIV'et XV' siècles, París-La Haye, 1970, p. 40).

26 Antoni RIERA I MELIS, Els pròdoms de les crisis alimentàries de la baixa edat mitjana a la Corona d'Aragó. 1: 1250-1300, "Miscel-lània en Homenatge al P. Agustí Altisent", Tarragona, 1991, p. 68.

${ }^{27}$ Vegeu, A. CURTO, op. cit., pp. 35-36. 
Gràfic 1. Evolució del consum i de les compres de forment de la Pia Almoina de Barcelona (1283-1345) ${ }^{28}$

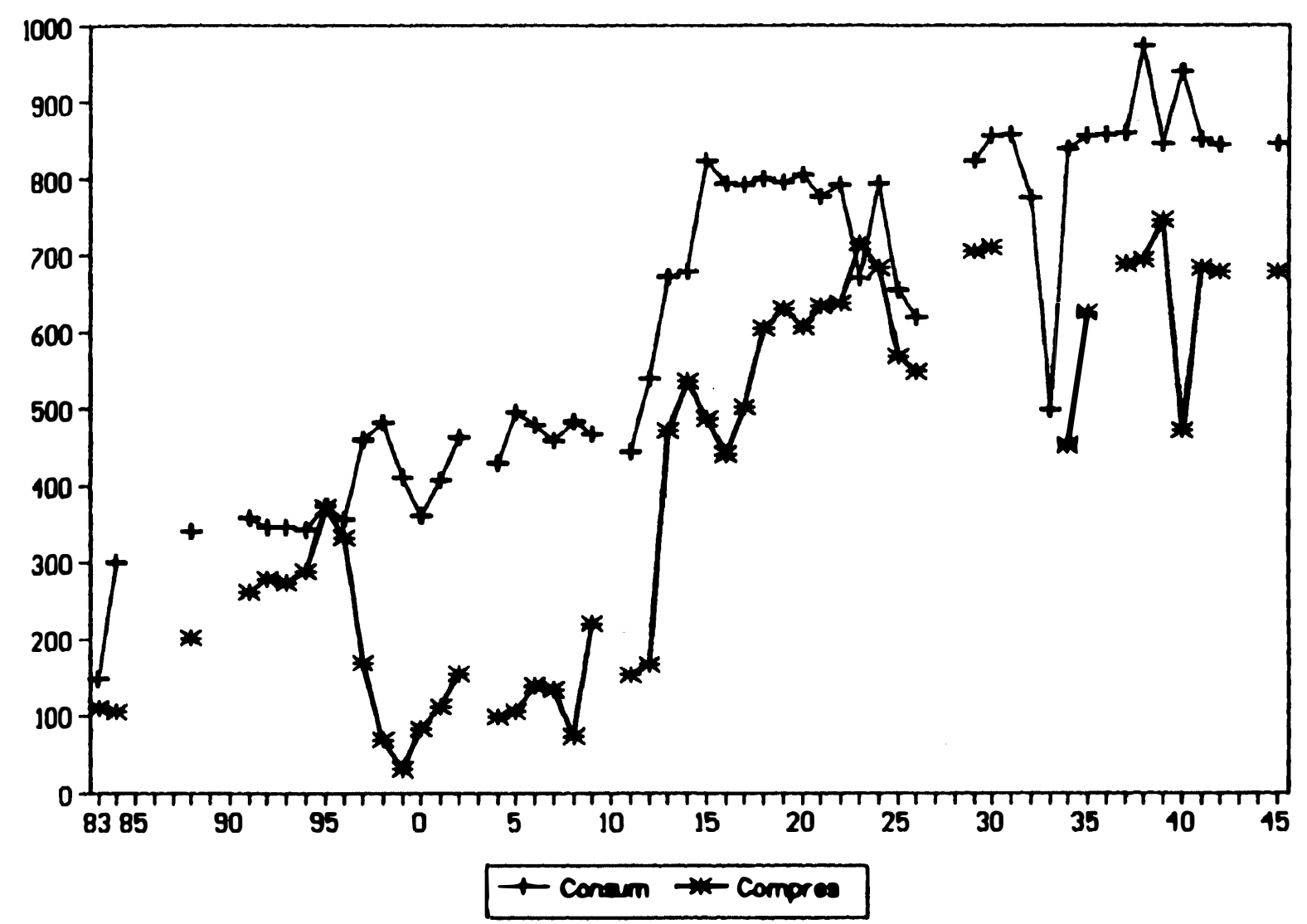

La Pia Almoina no tan sols obtenia el seu forment de les compres realitzades al mercat de Barcelona. Una part important del forment provenia de les rendes del seu patrimoni: dels «agrers» $\mathrm{i}$ censos de les seves terres $\mathrm{i}$ dels drets que tenia sobre la Quartera o Dret dels Cóps de Barcelona. La relació entre les compres i les rendes patrimonials (vegeu gràfic 1) no sempre fou igual en el període que hem analitzat. Valorar les rendes en espècie que la Pia Almoina obtenia i quin percentatge n'era consumit i quin altre comercialitzat és una tasca que escapa dels límits d'aquest treball, ja que això hauria suposat un estudi concret de la composició i gestió del patrimoni de la Pia Almoina. A partir del quadre 1 , es pot tenir una idea aproximada del valor de les rendes de

${ }^{28} \mathrm{El}$ consum està indicat per les quarteres de farina de forment panificades i les compres, per les quarteres de forment en gra. 
les terres de la Pia Almoina, tot restant de les quarteres mòltes les compres i els ingressos procedents de la Quartera. Diem una idea aproximada perquè la relació no és matemàtica, ja que no coneixem les rendes emmagatzemades per la Pia Almoina ${ }^{29}$. De la Quartera o Dret de Cóps de Barcelona la Pia Almoina obtenia 200 q. anuals en espècie repartides al llarg de l'any a raó de 20 q. mensuals entre juny i març, almenys a partir del $1313^{30}$.

Malgrat no haver estudiat el patrimoni de la Pia Almoina, semblen apreciar-se certes tendències generals que caldria comprovar: per una ban$\mathrm{da}$, les rendes en espècie provinents del patrimoni immoble de la Pia Almoina cobrien una part petita de les necessitats de la Pia Almoina, sobretot a partir de l'augment d'aquestes entre 1311 i 1315; sembla també que només es consumien les rendes provinents de la ciutat i del terme de Barcelona, de Palou i de Mollet; les altres eren normalment comercialitzades allà on es produïen en lloc de traslladar-les a Barcelona. Només s'observa un clar esforç per portar el major nombre de rendes en forment cap a Barcelona durant anys de crisi important (1334) i després del «mal any primer». (1339 i 1340).

29) Per començar, les fonts no són clares: en els primers llibres de comptes els ingressos $s$ 'anoten en espècie però no sabem la seva destinació -si eren consumits o comercializats- $i$ en les depeses només apareixen les partides de forment que generaven despeses de transport; en llibres posteriors, tots els ingressos en espècie eren valorats i comptabilitzats en diners a les entrades, i, si eren consumits, es comptava també el seu valor a les despeses; això fa que no sempre sigui facil distingir en l'apartat de compres si realment ho són. Sempre que ha estat possible hem extret aquests preus dels nostres càlculs, tot $\mathrm{i}$ que aquests són variables segurament perquè es feia una valoració segons el preu del moment. En alguns casos es poden, per tant, fer servir com a referència.

31) Aquestes $200 \mathrm{q}$. provenien de diferents donacions i compres fetes per la Pia Almoina. El 1267 Arnau, bisbe de Barcelona, comprà a Jaume I 100 q. de les rendes reials de la Quartera de Barcelona, i, amb el permís de l'arquebisbe de Tarragona (ACB, perg. PA, 4-26-3), va vendre 50 q. a la Pia Almoina i 50 q. a Pere de Torres, clergue, el qual les llegà a la Pia Almoina. Les altres 100 q. provenien també de la part reial de la Quartera que Alfons II alienà el 1289 a Pere Marquès. Aquest va vendre a Pere d'Espiells el 1292100 q. de la seva part i aquest últim les va vendre a la Pia Almoina el 1297 (ACA, Batllia, Cl. III núm. 19, f.1r-6v). Fins el 1313, en els llibres de comptes de la Pia Almoina no apareixen regularment les 200 q. Sembla que anteriorment rebien una part d'aquestes rendes en diners, encara que en els primers llibres de comptes moltes de les entrades només figuren amb el nom de qui la fa $i$, si no és coneix qui les administrava, és difícil distingir-les. 
Quadre 1. Quantitat de quarteres de forment comprades, ingressades del dret de Quartera i mòltes i quarteres de farina de forment panificades

\begin{tabular}{|c|c|c|c|c|c|c|c|c|c|}
\hline ANY & COMPRES & QUART. & MOLDRE & COURE & ANY & COMPRES & QUART. & MOLDRE & COURE \\
\hline 1283 & 110,5 & & 135 & 147,5 & 1317 & 502,3 & 200 & 705 & 791,5 \\
\hline 1284 & 106,5 & & 210,5 & 300,5 & 1318 & 604,7 & 200 & 805 & 799,5 \\
\hline 1288 & 202 & & 263 & 341 & 1319 & 630,2 & 200 & 860 & 794,5 \\
\hline 1291 & 261 & & 335,5 & 357,5 & 1320 & 606,8 & 200 & 835 & 805 \\
\hline 12 & 277,5 & & 396 & 345,5 & 1321 & 633 & 200 & 760 & 775,2 \\
\hline & 273 & & 375 & 346 & 1322 & 636,6 & 200 & 854 & 791 \\
\hline 12 & 289 & & 375 & 343 & 1323 & 715,7 & 180 & 847 & 668,5 \\
\hline 1 & 372 & & 437 & 372,7 & 1324 & 682,4 & 150 & 832 & 792 \\
\hline 1 & 333 & & 388 & 356,7 & 1325 & 568,2 & 200 & 708 & 654 \\
\hline 1297 & 168,1 & & 439 & 459,5 & 1326 & 547,4 & 193 & 596 & 618 \\
\hline 1298 & 69 & & 436 & 481,5 & 1327 & $?$ & 236 & ? & $?$ \\
\hline 1299 & 31 & 200 & 450 & 411 & 28 & ? & 234 & ? & $?$ \\
\hline 1300 & 83 & ? & 409 & 360,5 & 329 & 705,2 & 200 & 793 & 822,5 \\
\hline 1301 & 112,5 & 76,5 & 420 & 406,5 & 1330 & 709,8 & 200 & 924 & 854,5 \\
\hline 1302 & 155 & 112,5 & 442 & 462,5 & 1331 & ? & 200 & 665 & 856,5 \\
\hline 1303 & $?$ & 147 & ? & $?$ & 1332 & $?$ & 200 & 836,5 & 859 \\
\hline 1304 & 99,5 & 169 & 497 & 429,5 & 1333 & ? & 200 & 523 & 497,6 \\
\hline 1305 & 106 & ? & 508 & 495,5 & 1334 & 452,5 & 200 & 797 & 838 \\
\hline 1306 & 139,5 & $?$ & 510 & 478 & 1335 & 626 & 200 & 825 & 855,5 \\
\hline 1307 & 135 & 190 & 495 & 458,5 & 1336 & $?$ & 200 & ? & 857,5 \\
\hline 1308 & 73,5 & 195 & 525 & 482,5 & 1337 & 688 & 200 & 935 & 859,4 \\
\hline 1309 & 220,5 & 330 & 535 & 465,5 & 1338 & 693 & 200 & 815 & 971,5 \\
\hline 1310 & $?$ & & & ? & 1339 & 746 & 200 & 825 & 779,5 \\
\hline 1311 & 153 & 140 & 504 & 445 & 1340 & 472 & 200 & 1030 & 938 \\
\hline 13 & 166,5 & ? & 535 & 539 & 1341 & 682 & 200 & 785 & 849,5 \\
\hline 13 & 472 & 200 & 615 & 671,5 & 1342 & 677 & 200 & 810 & 843 \\
\hline & 5347 & 200 & 720 & 678 & 1343 & 2 & 200 & ? & $>$ \\
\hline & & 200 & 863 & 822,5 & 1344 & 2) & 200 & ? & 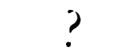 \\
\hline & 440,6 & 200 & 770 & 793,5 & 1345 & 678 & 200 & 820 & 845 \\
\hline
\end{tabular}

Per tant, la part més important de les necessitats de la Pia Almoina es cobria a partir de les compres fetes al mercat de Barcelona, ja que les mencions a d'altres indrets són mínimes. A més, pràcticament totes aquestes compres es 
feien en gra i la Pia Almoina comprà en comptadíssimes ocasions farina i mai pa.

Com ja hem indicat, per saber si el preu mitjà anual que podem obtenir de les diferents compres de la Pia Almoina reflectia més o menys el preu mitjà anual real, cal conèixer quan comprava el forment. A diferència de la Pia Almoina de Girona, la de Barcelona servia pa tot l'any ${ }^{31}$. Això ens porta a plantejar-nos en quines èpoques de l'any comprava el forment i si hi havia una política destinada a comprar-lo en les èpoques de l'any amb el preu més baix. Ja hem assenyalat que són pocs els llibres de comptes que datin les compres: pràcticament, només es poden datar dos períodes: 1288-1296 i 1337-1342. Tot i que és difícil comparar-les, perquè el volum de compres és molt diferent $\mathrm{i}$ en el primer cas respon a una època de baixos preus i en el segon d'alts, almenys ens demostra que les compres es feien al llarg de l'any; així, les mitjanes anuals reflecteixen un preu de tot l'any. Tampoc no s'observa una tendència a comprar el forment en les èpoques de preu més baix, més aviat al contrari (compareu gràfics 2 i 3). Per tant, sembla que la Pia Almoina acudia al mercat segons les necessitats del moment, sense una política de compra en els moments que el preu era més baix. Tot i això, els preus extrems a l'alça creiem que no hi són reflectits "2.

Cal preguntar-se si es poden generalitzar aquestes observacions a la resta de la sèrie malgrat que les compres no vagin datades. Per això compararem el nombre i el volum de les compres. Pel que fa al nombre (quadre 2), es poden establir tres etapes: 1288-1297, 1298-1312, 1313-1335 i 1337-1345 amb $18,9,41$ i 18 compres anuals, respectivament.

31 A Girona uns set mesos l'any (Christian GUILLERÉ, Una institució benèfica enfront les adversitats de l'època: la Pia Almoina de Girona (1347-1380), dins Diner, poder i societat a la Girona medieval del segle XIV, Girona, 1984, p.191.

32 Ja hem assenyalat que no es podem comparar exactament les mitjanes anuals calculades a partir de les dades dels molins amb les de la Pia Almoina, perquè les primeres representen un any de gener a desembre $\mathrm{i}$ les segones de maig a abril. Malgrat això, les diferències entre unes $i$ altres no són grans, a excepció dels anys de preus alts quan les dades de la Pia Almoina, tot i reflectir importants alces, no són tant extremes com les dels molins. 
Gràfic 2. Distribució anual de les compres de forment de la Pia Almoina (maig-abril)
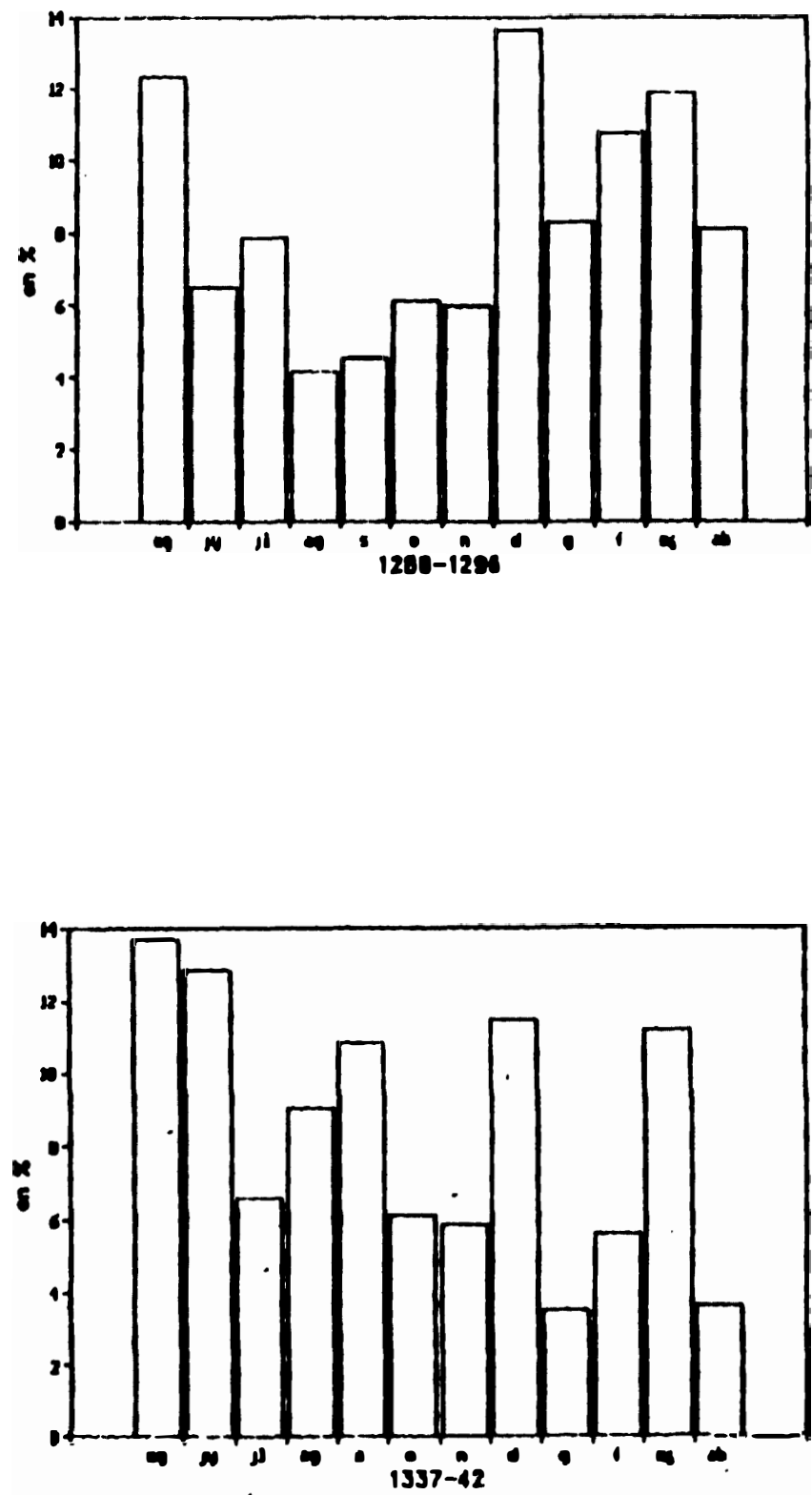
Quadre 2. Nombre anual de les compres de la Pia Almoina (12831345)

\begin{tabular}{|c|r|r|r|r|r|r|r|r|r|}
\hline ANY & N & ANY & N & ANY & N & ANY & N & ANY & N \\
\hline 1283 & 6 & 1298 & 4 & 1309 & 14 & 1320 & 45 & 1335 & 29 \\
1284 & 9 & 1299 & 2 & 1311 & 10 & 1321 & 60 & 1337 & 12 \\
1288 & 16 & 1300 & 7 & 1312 & 13 & 1322 & 52 & 1338 & 20 \\
1291 & 23 & 1301 & 7 & 1313 & 39 & 1323 & 37 & 1339 & 20 \\
1292 & 20 & 1302 & 11 & 1314 & 62 & 1324 & 24 & 1340 & 21 \\
1293 & 18 & 1304 & 8 & 1315 & 50 & 1325 & 35 & 1341 & 17 \\
1294 & 13 & 1305 & 10 & 1316 & 76 & 1326 & 17 & 1342 & 12 \\
1295 & 22 & 1306 & 12 & 1317 & 25 & 1329 & 40 & 1345 & 15 \\
1296 & 21 & 1307 & 10 & 1318 & 42 & 1330 & 40 & & \\
1297 & 12 & 1308 & 6 & 1319 & 27 & 1334 & 32 & & \\
\hline
\end{tabular}

En canvi, respecte al volum, dividirem la sèrie en dos grups: el primer el formen aquells anys on les compres oscil.len al voltant de les 170 q./any, i el segon grup amb 600 q./any, que subdividirem en dos perquè com veurem la política de compres varia molt. Si considerem aquestes compres respecte a les que podia fer qualsevol familia resident a Barcelona, evidentment la Pia Almoina només feia compres a l'engròs ${ }^{33}$. Creiem, però, que no es pot comparar. Cal cercar la pròpia lògica del major i detall dins la Pia Almoina. Per això, dins els tres grups esmentats hem calculat a partir de la mitjana anual les necessitats diàries, setmanals o mensuals de la Pia Almoina que són diferents en tots tres casos. Com es pot veure al quadre 3 , en el primer grup la majoria de les compres $(32,5 \%)$ representen les necessitats de tres setmanes de la Pia Almoina (10 q.); en canvi, en el segon grup, tot i mantenir-se un volum de compres majoritari igual (11 q.), aquestes representen les necessitats setmanals de la Pia Almoina. Finalment, en el tercer grup, el volum de les compres és molt més variat, amb un màxim que representa les necessitats de cinc setmanes $(25,6 \%)$, i amb un grup important de compres $(10 \%)$ que cobreixen les necessitats superiors a dos mesos.

i3 Una família de set persones podia necessitar 5 q. noves de forment a l'any, que són 6 q. de velles (Teresa-Maria VINYOLES I VIDAL, El pressupost familiar d'una mestressa de casa barcelonina per l'any 1401, dins La societat barcelonina a la baixa Edat Mitjana, "Acta/ Mediaevalia», Annexos d'Història medieval, annex 1, Barcelona 1982-83, p. 110). 
Quadre 3. Distribució de les compres de forment segons les necessitats de la Pia Almoina ${ }^{34}$

\begin{tabular}{|l|c|c|c|c|c|c|}
\cline { 2 - 7 } \multicolumn{1}{c|}{} & \multicolumn{2}{c|}{$1283-1312$} & \multicolumn{2}{c|}{$1313-1335$} & \multicolumn{2}{c|}{$1337-1345$} \\
\cline { 2 - 7 } \multicolumn{1}{c|}{} & Q. & F. & Q. & F. & Q. & F. \\
\hline \multirow{2}{*}{ dia } & 0,5 & 0,7 & 1,6 & 4,1 & 1,8 & 0,9 \\
1 setmana & 3 & 4,4 & 11 & 60,2 & 12 & 20,5 \\
2 setmana & 7 & 8,4 & 22 & 21,7 & 24 & 15,4 \\
3 setmana & 10 & 32,5 & 33 & 7 & 36 & 17,1 \\
4 setmana & 14 & 12 & 44 & 1,9 & 48 & 8,5 \\
5 setmana & 17 & 12,4 & 55 & 2,2 & 60 & 25,6 \\
6 setmana & 21 & 16,4 & 66 & 0,8 & 72 & 0,9 \\
7 setmana & 24 & 2,6 & 77 & 0,3 & 84 & 0,9 \\
8 setmana & 28 & 2,2 & 88 & 0,3 & 96 & 0 \\
$>8$ set. & 28 & 8 & $>88$ & 1,5 & $>96$ & 10,3 \\
\hline
\end{tabular}

Pel que anem dient fins ara, totes tres etapes vindrien caracteritzades amb compres durant tot l'any però amb un període 1313-1335 de compres al detall (necessitats setmanals); els altres dos amb compres de necessitats mensuals, amb la diferència que en el període 1336-1345 hi ha compres més grans.

Resumint les dades que ens aporta el nombre, el volum i la distribució anual de les compres, podem establir dues etapes generals a partir del volum global de les necessitats de forment de la Pia Almoina:

1. 1283-1312: amb unes necessitats al voltant de les $400 \mathrm{q}$. anuals que comporten unes compres de 170 q. l'any. A partir del nombre podem establir dos subgrups: les compres.

a) 1288-1297: s'observa clarament una distribució al llarg de l'any de

b) 1298-1312: és l'etapa on les compres representen un volum menys important en relació a les necessitats, cosa que es reflecteix amb un nombre de compres inferior; per tant, és l'etapa on els preus s'han de considerar amb més precaució.

${ }^{34}$ A la primera columna es representen les necessitats de la Pia Almoina en quarteres segons el volum de compres anual, i a la segona el percentatge de compres que respon a cada necessitat. 
2. 1313-1345: a partir del 1313 es doblen les necessitats de la Pia Almoina (800 q. anuals) que porten a necessitar un volum de compres de 600 q. anuals. Davant aquest fet la Pia Almoina actuà de dues maneres diferents:

a) 1313-1335: manté el mateix volum de compres que en l'etapa anterior cosa que porta a cobrir necessitats setmanals; això provoca un augment del nombre de compres $i$, per tant, les mitjanes anuals reflectiran molt millor el preu real.

b) 1337-1345: època de reducció del nombre de compres i augment del volum d'aquestes tot $\mathrm{i}$ que segueixen estan repartides durant tot l'any.

Per tant, com que el volum de les compres de la Pia Almoina respon a grans necessitats, sofreix les incidències del mercat de forma semblant a la major part dels habitants de la ciutat. Tot i que pot tenir en casos extrems altres mecanismes com pot ser un intent de portar forment procedent de les seves rendes d'altres indrets.

Finalment, cal valorar si en comprar quantitats més grans respecte a les que podien adquirir la resta de barcelonins, la Pia Almoina obtenia el forment a uns preus més baixos, sobretot a partir de 1337 quan, com hem vist, s'observa un augment del volum de les compres. Això ens porta a analitzar a qui compra el forment. Les anotacions dels venedors del forment que compra la Pia Almoina no apareixen fins l'any 1317, però no serà fins a la segona meitat de la dècada dels 30 quan les anotacions són exhaustives indicant a més l'ofici i l'origen del venedor; fins i tot en alguns casos s'anota si aquest és un intermediari. Malgrat, la desigual informació que ens donen els diversos registres sembla haver-hi una diferència clara entre el registres anteriors al «mal any primer» $\mathrm{i}$ els posteriors que coincideix amb el canvi de política de compres de la Pia Almoina. En l'etapa anterior apareixen un important nombre de compres, normalment en petites quantitats, procedents d'altres institucions del capítol, principalment de la Casa de la Caritat ${ }^{39}$ però també dels pabordes, del majordom del bisbe, etc. Sembla que els preus són els mateixos que en el mercat perquè no es diferencien dels altres, encara que tenen l'avantatge d'estar lliures de les imposicions municipals. En canvi, en la segona etapa, caracteritzada per una reducció del nombre de compres a l'any $i$ en consequiència un augment de volum de cada compra, aquestes es realitzen pràcticament totes a formenters, ofici especialitzat en la venda de forment.

És difícil poder establir si la Pia Almoina obtenia uns millors preus en fer compres de forment al major. L'únic any que podem comparar els preus diaris

is Per a les diferències entre la Casa de la Caritat i la Pia Almoina, vegeu J. BAUCells: La gènesi de la Pia Almoina, pp. 20-21. 
del forment a través dels llibres de comptes dels molins i el de les compres de la Pia Almoina és el 1339. En aquest cas, s'observa que el preu coincideix pràcticament tot l'any, però quan el preu del forment pujà a finals d'any a uns preus mitjanament alts la Pia Almoina comprà forment a dos preus: uns de semblants als dels molins i uns altres molt més barats, sobretot en aquelles compres fetes a formenters amb els quals ja havia comprat importants quantitats la resta de l'any.

Per tant i per concloure, podem dir que els llibres de comptes de la Pia Almoina de Barcelona ens mostren uns preus que reflecteixen bastant bé la seva variació anual, ja que les compres es distribueixen al llarg de l'any. A més, no existeix, almenys fins després del "mal any primer», una política de compres destinada a obtenir el forment a preus més baixos. Així, la diferència més important amb la resta d'habitants de Barcelona resideix en el volum de les compres, sobretot a partir de l'any 1337. Finalment, cal assenyalar que el valor representatiu de les mitjanes anuals calculades a partir de les compres de la Pia Almoina varia segons els anys. Probablement, els preus més representatius són els del període 1313-1335 i els menys representatius els de 1298-1312.

\section{LES MESURES}

Com és de sobra conegut, la característica principal de les mesures medievals és la seva enorme complexitat, a causa de la gran diversitat local i de l'existència de diverses mesures per a cada producte. El cas dels molins de Barcelona és força il·lustratiu, ja que, com veurem, tenien la seva pròpia mesura per al forment. A la ciutat comtal, la mesura per al gra més utilitzada era la quartera, dividida en 12 quartans $i$ amb una capacitat de $69,5181 .{ }^{36}$. A principis del segle XIV, existien, però, dues quarteres diferents: una per a l'ordi, igual a l'anterior, i una altra per al forment, dividida en 10 quartans. El 1346 s'intentà unificar les dues quarteres, equiparant la de forment a la d'ordi ", però sembla que continuà havent-hi dues quarteres diferents, almenys fins el $1378^{38}$. En els molins reials del Rec Comtal s'utilitzava la quartera de forment,

36 Claudi Alsina; Gaspar FeliU; Lluís Marquet, Pesos, mides i mesures dels Països Catalans, Barcelona, 1979, pp.209-214. Una quartera de forment podia pesar entre 54 i 55 quilograms (Santiago LLENSA I DE GELCEN, Breve bistoria de las medidas superficiales agrarias de la antigüedad y estudio particular de aquellas cuyo uso es tradicional en Catalunya, Cámara oficial Sindical agraria de Barcelona, Publicaciones divulgadoras, XII, 1951, p. 39).

${ }^{37}$ ACA, C, reg.955, f.57v-58v (13.6.1346).

38 ACA, C, reg.933, f.30v (11.11.1378), transcrit per Antonio Ma ARAGó; Mercedes 
però el quartà era diferent: en lloc de ser $1 / 10$ de la quartera, n'era $1 / 9$. El fet que hi haguessin pagaments fixats en quartans dels molins, alguns d'establerts des del segle XII, va fer que, malgrat que la mesura no s'utilitzés com a tal al segle XIV, hom el continués calculant per a determinar el valor d'aquests pagaments. Per això, trobem una equivalència entre l'antiga i la nova quartera $i$ entre el quartà de la ciutat i el dels molins. Així, com es pot observar en el quadre 4 , el quartà en què es dividia la quartera antiga i la nova era el mateix; la diferència entre una i altra estava en el fet que la nova en tenia 12 i la vella 10. Ja hem assenyalat que la quartera vella i la dels molins era la mateixa, però subdividida en 9 quartans ${ }^{39}$.

La Pia Almoina utilitzava també la quartera de Barcelona però, en canvi, el quartà era poc emprat. Normalment ens apareix, com a submúltiple de la quartera, una part d'aquesta; però en el període que va entre 1313 i 1330 s'utilitzà freqüentment una altra mesura, el cóp. A partir d'aquestes referències podem establir que un cóp representava $1 / 16$ part de la quartera vella ${ }^{40}$.

Quadre 4. Equivalències entre les quarteres i quartans de forment a Barcelona (segle XIV)

\begin{tabular}{|c|c|c|c|c|c|c|}
\hline & $\begin{array}{l}\text { Quartera } \\
\text { vella }\end{array}$ & $\begin{array}{l}\text { Quartà } \\
\text { de B. }\end{array}$ & $\begin{array}{l}\text { Quartà } \\
\text { molins }\end{array}$ & Cóp & 1. & $\mathrm{Kg}$ \\
\hline $\begin{array}{l}\text { Quartera nova } \\
\text { Quartera vella } \\
\text { Quartà de B. } \\
\text { Quartà molins } \\
\text { Cóp }\end{array}$ & 1,2 & $\begin{array}{l}12 \\
10\end{array}$ & $\begin{array}{c}10,8 \\
9\end{array}$ & $\begin{array}{c}16 \\
1,6\end{array}$ & $\begin{array}{r}69,518 \\
57,932 \\
5,793 \\
6,436 \\
3,621\end{array}$ & $\begin{array}{l}54-55 \\
44-45 \\
4,5 \\
5 \\
2,8\end{array}$ \\
\hline
\end{tabular}

Costa, Privilegios reales concedidos a la Ciudad de Barcelona, "CoDoIn ACA», XIIII, Barcelona 1971, pp.165-167, en aquest document apareix insert el de 1346.

39 «Item, de la mesura nova que vuy és e corre per Barcelona leve $\cdot n$ hom II quartans $e$ prea $\cdot$ Is hom segons que val la quartera que vuy és en Barcelona; e d'açò qui roman fa $n$ hom IX parts e la novena és del quartà e dóna-la hom en aquells qui prenen quartà en lo mulnar reyal de Barcelona» (ACA, Batllia, Cl.III núm. 33, f.29r, 1384-86?).

to No queda clar com afectà el cóp la modificació de la quartera; l'única referència que tenim per a una època posterior al canvi és de principis del segle $\mathrm{XV}$ i dóna una equivalència d'1/17, cosa que suposaria que el valor del cóp també va canviar (ACA, Batllia, Cl.III, núm. 3 , f.35r). 
L'existència del quartà dels molins es troba documentada des del segle XII en les concessions a perpetuïtat de les mulneries dels molins reials. A través dels censos que obtenia la Canonja de la Seu de Barcelona del casal dels Molins del Mar i d'un perpetual del monestir de Santa Eulàlia del Camp, es poden fer algunes equivalències entre les mesures del segle XIV i les del XII. S'ha de tenir en compte que només afecten Barcelona i que caldrà relativitzar-les ja que es basen en dues úniques referències. Així, a partir dels censos del casal del Molins del Mar, podem establir que un cafís era igual a 12 sesters i a 96 quarteres ${ }^{41}$.

El perpetual del monestir de Santa Eulàlia del Camp, en canvi, ens relaciona el sester amb els quartans dels molins ${ }^{42}$ :

1 sester $=4$ mitgeres $=8$ quarteres

1 mitgera $=2$ quarteres $=18$ quartans dels molins.

Per tant, la quartera de Barcelona mencionada al segle XII havia de ser la quartera vella de 10 quartans, a la ciutat, i de 9, als molins. XIII)

Quadre 5. Equivalències de les mesures de forment a Barcelona (segles XII-

\begin{tabular}{|c|c|c|c|c|c|c|}
\hline & Sester & Mitgera & $\begin{array}{l}\text { Quartera } \\
\text { vella }\end{array}$ & $\begin{array}{l}\text { Quartà } \\
\text { de B. }\end{array}$ & $\begin{array}{l}\text { Quartà } \\
\text { molins }\end{array}$ & 1. \\
\hline $\begin{array}{l}\text { cafís } \\
\text { sester } \\
\text { mitgera } \\
\text { quartera }\end{array}$ & 12 & $\begin{array}{r}48 \\
4\end{array}$ & $\begin{array}{r}96 \\
8 \\
2\end{array}$ & $\begin{array}{r}960 \\
80 \\
20 \\
10\end{array}$ & $\begin{array}{r}864 \\
72 \\
18 \\
9\end{array}$ & $\begin{array}{r}5561,472 \\
463,456 \\
115,864 \\
57,932\end{array}$ \\
\hline
\end{tabular}

${ }^{41}$ En l'establiment de 1094, es fixà un cens de dos cafissos de blat anuals pagats en quatre parts de 6 sexters (ACB, LAEC, Lib.I, núm. 621, f.229-230, 12.1.1094, transcrit per Francesc CARRERAS I CANDI, Notes sobre los origens de la enfiteusis en lo territori de Barcelona, «Revista jurídica de Catalunya», 15-16 (1909-1910), p.242-243); en canvi, el 1165, el cens fou de 2 cafissos i 3 sexters anuals, també en quatre terminis de 6 sesters i 6 quarteres (ACB, LAEC, Lib. I, núm. 69 f.35r, 1.6.1165); equivalències citades per: Roland VIADER, Les contrats agraires des archives capitulaires de Barcelone (XI '-XIII' siècle), Mémoire de mâtrise inèdita, Toulouse, 1990, p.80.

${ }^{42}$ Pere I confirmà al monestir de Santa Eulàlia del Camp la donació d'Alfons I que, entre d'altres coses, concedia 3 sesters de blat anuals i 10 sous mensuals sobre les rendes dels molins reials de Barcelona (ACA, Batllia, Cl.II, Ba núm. 1, f.76r, 1210); posteriorment, hi hagué un conflicte entre Ramon de Plegamans, en nom del rei, i el prior de Santa Eulàlia del 
També trobem, en relació als molins reials de Barcelona, pagaments fixats en quarteres d'ordi, establerts des del final del segle XII. En aquest cas no hi ha equivalències, perquè sembla que la quartera no varià. Així, el sistema de dos quarteres que trobem a principis del segle XIV seria un sistema vigent almenys des del segle XII. Això no vol dir que durant el segle XIII no hi poguessin haver altres mesures ni que aquestes fossin les més comunes ${ }^{43}$.

A la Barcelona del segle XIV les mesures més normals per a la farina eren les típiques de pes: carga, quintar, rova i lliura ${ }^{44}$. Malgrat tot, també s'utilitzaven mesures de capacitat, principalment la quartera. Així, la Pia Almoina emprava la quartera per a mesurar la farina que enviava als forners per a fer el pa. No hi havia a Barcelona una quartera específica per a la farina, sinó que s'utilitzava la mateixa que per als grans. Però, evidentment, una mateixa quantitat en pes de gra i de farina són dues quantitats diferents en capacitat. Sembla que la quartera per a la farina s'empreava en el sentit d'una quartera de gra però mòlt. Així, s'entendria l'ús que en feia la Pia Almoina ja que li permetia controlar les entrades en gra i les sortides en farina. A partir del 1337 utilitzà també de manera sistemàtica la "pesa» i s'anotava sempre la seva equivalència en quarteres. Aquesta havia de ser una mesura de pes i el seu valor més normal era de 2 peses per quartera de farina ${ }^{45}$. No hem trobat, però, cap equivalència entre la "pesa" $i$ les mesures típiques de pes, però sí entre la quartera i el quintar. Aquest últim, com a mesura de pes de la farina de la Pia Almoina, apareix en poquíssimes ocasions $i$, en general, hom li atorga un valor aproximat al de la quartera ${ }^{46}$; però en un cas se'ns en dóna una equivalència exacta: 4 quintars i 3 roves de farina igual a $4,5 \mathrm{q}^{47}$. Això ens dóna un pes aproximat de $44 \mathrm{~kg}$ per quartera de farina.

Camp, sobre el pagament de 20 sous i 2 quarteres de forment mensuals que el monestir considerava que havia de rebre. Els àrbitres eclesiàstics, Ramon Riera, canonge de Barcelona, i Berenguer Gerard, donaren la raó al monestir després d'escoltar diferents testimonis (ACA, Batllia, Cl.II, Ba núm. 1 f.39r-39v, 28.5.1238).

43 Així, el 1246 el bisbe i la Canonja de Barcelona utilitzen també el «pugnario» (punyera), equivalent a $1 / 3$ d'una quartera (ACB, perg. PA, 4-26-1).

441 carga $=3$ quintars $=12$ roves $=312$ lliures $=124,8 \mathrm{~kg}$. (C. AlSINA; G. FeliU; L. MARQUET, op. cit., p.134). Així, per exemple, mentre totes les imposicions municipals del segle XIV sobre els grans es fixen en quarteres, sobre la farina es fa en quintars (ja en la primera coneguda de 1315:A. ARAGó; C. CosTA, op. cit., p.39).

4s L'equivalència no és sempre exacta, però les diferències són mínimes.

${ }^{46}$ Apreciació que també observa Eva SERRA I PUIG, Els cereals a la Barcelona del segle XIV, dins Alimentació i societat a la Catalunya medieval, "Anuario de Estudios medievales», annex 20, Barcelona, 1988, p.89.

${ }^{47}$ ACB, PA-1330-D, s/f. 
Finalment, queda per establir l'equivalència entre el gra i la farina. En mesura de pes, el gra portat a moldre i la farina resultant havien de tenir un pes semblant: així s'indica en les ordinacions que regularen la Casa del Pes de la farina, on es controlava el gra portat a moldre i la farina que en tornava ${ }^{48}$; per tant, una quartera de forment havia de fer aproximadament uns $44 \mathrm{~kg}$, valor que coincideix amb les referències al pes de la quartera nova ${ }^{49} \mathrm{i}$ que dóna una densitat del forment dins el marges medievals $(76 / 100)^{s 0}$.

\section{ELS IMPOSTOS SOBRE LA COMPRA-VENDA DE FORMENT}

Un factor important que actua sobre el cost real del forment és la fiscalitat que pesava sobre la seva comercialtizació. Malgrat que, almenys en teoria, els impostos sobre la comercialització dels productes no queden integrats en aquest, cal conèixer-los per saber el cost real ${ }^{\text {s1 }}$.

De l'enrevessat conjunt d'impostos medievals que gravaven el mercat barceloní pràcticament només coneixem amb una certa profunditat les imposicions municipals des del primer terç del segle XIV a partir de l'estudi de Jean Broussolle ${ }^{\prime 2}$. Però la fiscalitat anterior a aquesta època és poc coneguda. A més,

${ }_{48}^{4}$ Segons el privilegi reial del 3.4.1376, els encarregats de la Casa del pes de la farina havien de pesar: «tot lo gra qui serà portat per molre als dits molins e façen escriure tot lo pes del dit gra... E aquell que pesaran tornen a pesar com serà mòlt, ço és, la farina que aportaran per tal que semblant pes que serà lo gra pes la farina, salvant una libra per quartera la qual és acostumada de donar per lo polveratge" (A. ARAGO; M. CosTA, op. cit., doc.256, p.152). En aquest cas "polvoratge» no té res a veure amb el dret de moltura; més aviat fa referència a una quantitat pagada per a la realització d'una tasca penosa a causa de la pols, com podria ser la d'espolsar el blat (agraïm les indicacions de Teresa Gràcia i el Dr. Joan Bastardes). A Aragó també trobem una ordinació semblant i amb un «espolvoreo" que suposa una proporció igual: 0,9\% (Pablo LARA IZQUIERDO, Sistema aragonés de pesos y medidas. La metrología aragonesa y sus relaciones con la castellana, Zaragoza, 1984, p.179).

${ }^{49}$ Entre 54 i 55 kg, S. LlenSA, op. cit., p.39.

so P. LARA, op. cit., p.183. Finalment, també apareixen en els llibres de comptes de la Pia Almoina algunes equivalències de mesures d'altres poblacions de Catalunya. La millor documentada és la quartera de Granollers: 1 q. $=8$ qà. $=43,449$ l. (igual a la referència donada per la q. sense cóp de Granollers per: C. AlSINA; G. FeliU; L. MARQUET: op. cit., p.309).

"Així, en els llibres de comptes de la Pia Almoina, sempre es desglossa el preu dels impostos.

52 Jean BROUSSOLLE, Les impositions municipales de Barcelone de 1328 à 1462, «Estudios de Historia Moderna», V (1955), pp. 3-164. 
la síntesi que el mateix Broussolle fa dels orígens de la fiscalitat municipal a partir dels treballs de Carreras Candi no ha fet més que enfosquir un tema ja de per si complicat ". Les línies que segueixen, lluny d'oferir una anàlisi exhaustiva, volen ser només una visió general aplicada a un producte concret, els cereals. Són els primers resultats d'un projecte d'investigació en curs sobre la fiscalitat reial a la ciutat comtal durant la baixa edat mitjana.

Brousssolle considera que les imposicions municipals deriven dels nous impostos introduïts per Ramon Berenguer III ("usatici novi»), encara que molt evolucionats ${ }^{54}$. Però, la realitat és que aquests usatges no tenen res a veure amb la fiscalitat municipal, perquè formen part dels drets comtals sobre la lleuda de Barcelona ". Per tant, eren una de les rendes procedents del patrimoni reial i cal distingir-les clarament de la fiscalitat municipal. Fins al segle XIII tots els impostos nous i vells sobre el mercat formaven part de la fiscalitat comtal i n'eren una de les rendes més lucratives ${ }^{36}$. La majoria d'aquests impostos es troben descrits en el text del repartiment de la lleuda de Barcelona entre Guillem de Mediona i Jaume I, que inclou a part de la lleuda altres impostos sobre el mercat: passatges, mesuratges i drets sobre taules i oficis "s?

Aquesta fiscalitat comtal no derivarà cap a la fiscalitat municipal. La seva evolució ve determinada per dos fets clars: per una banda, la fixació definitiva d'aquests impostos ${ }^{58} ; \mathrm{i}$, per l'altra, els successius enfranquiments del pagament de lleuda i mesuratge, principalment, dels mateixos ciutadans de Barcelona el $12322^{\prime 9}$. Aquest fet crearà el que podríem dir-ne un espai fiscal per on penetrarà la nova fiscalitat municipal.

Les primeres mencions d'uns impostos municipals sobre el mercat són de

${ }_{33}$ Broussolle resumeix la descripció de les múltiples imposicions que fa Carreras Candi (Francesch Carreras CANDI, La Ciutat de Barcelona, dins Geografia general de Catalunya, Barcelona, s/d., pp.630-676).

${ }^{54} \mathrm{~J}$. BROUSSOLle, op. cit., p.13.

ss Vegeu Jaume SOBReQUÉS I CAllicó; Sebastià Riera I Viader, La lleuda de Barcelona del segle XII, "Estudis Universitaris Catalans», XXVI (1984), pp.329-346.

so La millor síntesi sobre la fiscalitat comtal de Barcelona als segles XII i XIII: Stephen P. BENSCH, Economic expansion and familiy formation in medieval Barcelona, 1100-1291, 2 vols., University of California, Berkeley, 1987, vol. I, pp.123-202.

"7 Vegeu: Miguel Gual Camarena, Vocabulario del comer-cio medieval, Barcelona, 1976, pp.56-65. A part d'aquests hi havia també una lleuda sobre "peixos i olles» i sobre les moles, uns mesuratges («quartera», "quintar» $\mathrm{i}$ «roldor») i els drets sobre la peixateria i les carnisseries.

${ }^{58}$ En el cas de la lleuda de Barcelona, amb el repartiment entre Jaume I i Guillem de Mediona el 1222. La resta també es fixà entre finals del segle XII i principis del XIII.

59. Ambrosio Huicu Miranda; María Desamparados Cabanes Percourt, Documentos de Jaime I de Aragón, 4 vols., València, 1976, vol. I, doc. 167. 
finals del segle XIII. «Cises», «almoynes», «ajudes» o imposicions eren els noms que rebien aquests impostos transitoris fins que, a partir del 1330, es convertiren pràcticament en permanents. En general, gravaven la compravenda d'un determinat conjunt de productes que, a diferència de la fiscalitat comtal, era variable igual com les tarifes de l'impost, depenent de les necessitats financeres del municipi. Aquest conjunt d'imposicions serà la principal font de finançament del municipi barceloní, el qual optà per l'impost directe només en comptadíssimes ocasions. El fet que la ciutat tingués unes fonts de finançament contínues des del 1330 no ha d'amagar que la fiscalitat municipal depenia directament de la voluntat reial i derivava de les seves necessitats financeres: les «ajudes» atorgades per la ciutat al rei eren la base de les finances municipals ja que, a canvi de les "ajudes», el monarca concedia el permís de collir imposicions. La ciutat ens apareix, així, com un gestor de la fiscalitat reial: era aquesta que recaptava uns impostos que després pagava al rei. Però, a diferència del simple gestor, la ciutat participava també en la decisió de la quantia de l'impost i de la modalitat de cobrament a través de la negociació directa amb el rei o de les Corts. I el pagament continuat d' «ajudes» al rei permeté també, a la ciutat, una certa autonomia financera $i$, així, poder destinar una part de les imposicions a les necessitats de la ciutat, com podien ser les subvencions per a importar cereals o algunes obres públiques ${ }^{60}$.

El forment era un dels productes gravat pels dos tipus de fiscalitat: la comtal, a través de la Quartera (o Dret de Cóps) i de la lleuda de la farina, i la municipal, a través de la imposició també anomenada de la quartera o la de la farina.

La Quartera de Barcelona s'inclou en el grup dels mesuratges de la ciutat. Per tant, es pagava el dret de la Quartera quan es mesurava el forment amb la quartera reial, l'oficial. Com que, en principi, tothom qui venia cereals estava obligat a mesurar el forment a la Quartera, s' ha de considerar aquest mesuratge com un impost general sobre la compra-venda de cereals. Com ja hem assenyalat, els ciutadans de Barcelona aconseguiren el 1232 la franquesa de tota lleuda i mesuratge, que suposà en el cas de la Quartera l'enfranquiment de l'obligació d'anar-hi a mesurar. De les tarifes d'aquest impost només coneixem una referència de principis del segle XV: «paguen los ciutadans de Barcelona de cascuna cortera, lo quart de hun cóp, e ha la cortera XVII cóps; e si és hom stranger, pagua per cascuna cortera, mig cóp, en tant que 1 stranger pagua lo doble; emperò, no pagua algun dret sinó lo venedor com lo comprador no

(1) Malgrat tot, quan la ciutat vulgui realitzar una obra de certa importància haurà de cercar el permís reial per crear noves imposicions. 
pagua res» ${ }^{61}$. Per tant, pagaven un 2,95\% els ciutadans de Barcelona que utilitzessin la mesura, i un 5,9\% tots els estrangers (aquells que no tenien franquesa) que venguessin cereals a Barcelona. A principis del segle $\mathrm{XV}$, aquest dret podia suposar unes rendes al voltant de $32.000 \mathrm{~s}$. l'any ${ }^{62}$. Aquest impost probablement té el seu origen a finals del segle XI o principis del XII, amb la introducció dels "usatici novi» de Ramon Berenguer III $i$, per tant, era un impost comtal. Però, a causa de les successives alienacions a l'arribar al segle XIV el rei no posseïa cap part d'aquesta renda ${ }^{63}$.

La farina també estava gravada amb un impost comtal, però aquest està menys clar. Per una banda, a la lleuda de Mediona es fixava un impost sobre la venda de farina, del qual el rei no obtenia cap renda ${ }^{64}$. Per altra banda, sabem que el lloc de venda principal de farina era la Farneria del Palau reial de Barcelona d'on el rei obtenia unes rendes que també s'anomenava lleuda de la farina ${ }^{\text {ss. }}$.

Les imposicions municipals també afectaven la compra-venda de cereals i de farina. Aquesta imposició, junt amb la de la carn i del vi, foren les tres imposicions principals i les més rendibles. Al segle XIV, apareixen regularment a partir de $1314 \mathrm{i}$ definitivament, a partir de $1330{ }^{\circ 6}$. Les tarifes d'aquesta

${ }^{61}$ ACA, Batllia, Cl. III, núm. 3, f.35r.

${ }_{62}$ ACA, Batllia, Cl. III núm. 3, f.35r.

${ }^{63}$ Al segle XIII el rei només posseïa 3/16 parts de la Quartera: de la resta, el bisbe de Barcelona en posseïa la meitat $i$ les altres $5 / 16$ parts apareixen en mans de diferents famílies jueves relacionades amb préstecs a Ramon Berenguer IV i Alfons I. Les 3/16 parts que posseïa al segle XIII foren venudes el 1289 a Pere Marquès, part que es recuperà posteriorment el 1429 (ACA, Batllia, Cl.III, núm. 19, f.1r-6v).

64 "Tota farina quam extraneus homo adducat, tam per mare quam per terra, de unaquaque salmata unam pesam; et est $\mathrm{G}$. de Mediona; et si descendit salmata de tribus quarteriis inferius, donet duas partes de pesa. Et omnis homo istius ville qui adducat farinam ad revendere, de una salmata media pesa tam per mare quam per terram; et hoc est intelligere quod si salmata descendat de tribus quarteriis inferius, donet duas partes de media pesa: et in hac tota farina accipit P. R. Alfocho terciam partem, et alia tota est G. de Mediona» (M. Gual Camarena, op. cit., pp.62-63).

6s ACA, C., reg.19, f.1v-3r; de les rendes de la Farneria s'ha conservat molt poca documentació, ja que generalment s'arrendaven junt amb els molins reials de Barcelona.

${ }^{66}$ Segons les ordinacions municipals durant la segona dècada del segle XIV hi hagueren imposicions el 1314, 1315, 1316, 1318 i 1319 (F. RoCA, op. cit., vol.III, pp.16351649). De les de 1315 tenim els capítols a ACA, C, perg. Consell de Cent, n 116 (A. ARAGÓ; M. Costa, op. cit., doc.63). A través dels llibres de comptes de la Pia Almoina també es poden resseguir les imposicions sobre el forment; s'ha de tenir en compte, però, que en alguns casos el fet que no es mencionin imposicions no vol dir que no n'hi hagués, ja que sovint les institucions eclesiàstiques eren franques sempre que les compres es fessin per al seu propi consum. Segons aquests llibres hi hagué imposicions el 1315, 1316 i 1319 i en tots els casos 
imposició variaven segons el tipus de cereal, sent per a la quartera de forment i pel quintar de farina de forment de $2 \mathrm{~d}$. que pagaven tant el comprador com el venedor. Aquestes tarifes es doblaren a partir de 1330 , i al 1343 passaren a $4 \mathrm{~d}$. el comprador $\mathrm{i}$ de $2 \mathrm{~d}$. el venedor ${ }^{67}$.

Aquestes imposicions que, com es pot veure, gravaven la compra-venda de cereals, sofriren un canvi important als anys 50 del segle XIV, que no s'ha de confondre, com fa Broussolle, amb un desdoblament de l'impost creant-ne un per a la compra-venda de grans (la quartera) i un altre per a la compra-venda de farina ${ }^{68}$. El que realment succeí, fou que la imposició es fixà no pas sobre la compra-venda sinó sobre tot el gra que es portés a moldre. Aquest canvi, probablement es realitzà a Barcelona el 1353 a partir de les imposicions aprovades per les Corts de Vilafranca del Penedès per pagar una ajuda del braç reial ${ }^{69}$. Aquest canvi és important ja que per primer cop es gravava tot el gra consumit a Barcelona $\mathrm{i}$ incloïa, per tant, no sols el gra que una persona comprava sinó també aquell que produïa.

el comprador, la Pia Almoina, pagà 2 d./q. En la dècada següent hi hagué imposicions pràcticament durant tot el període a excepció de petits intervals.

67 Aquestes són les tarifes principals, ja que en alguns casos hi havia varacions segons si, per exemple, el comprador era flequer o forner (vegeu J. BROUSSOLLE, op. cit., pp.5155).

${ }^{68}$ Ibidem, p.50-59.

${ }^{69} \mathrm{Ja}$ a les Corts de Perpinyà de 1351 s'havia aprovat una imposició sobre el gra portat a moldre, però Barcelona pactà amb Pere III posteriorment per adaptar les noves imposicions fixades a les Corts amb les que ella ja cobrava $i$, pel que fa als grans, es mantingué un impost sobre la compra-venda augmentant-ne el valor (AHCB, Llibre vermell, II, f. 158r-161r).

La introducció d'aquesta nova imposició no suposà l'eliminació immediata de l'anterior. La percepció de la imposició de la quartera s'havia interromput, ja que el 1348 només es cobraren dues imposicions una sobre la carn i una altra sobre el vi (AHCB, Consellers, C-VI $\mathrm{n}^{\circ} 5, \mathrm{f} .40 \mathrm{r}-42 \mathrm{r}$ ) i no tornà a aparèixer fins el juliol de 1350 (Ibidem, f.97r-98r) destinada a sufragar les despeses que suposà la reforma de la Plaça del Blat, imposició que només pagaven els venedors de cereals a raó d'l d. per q. de forment i malla per q. d'altres cereals. Aquesta imposició fou augmentada el 1351 pels canvis mencionats de les Corts de Perpinyà; tanmateix, quan finalment s'adoptà la nova imposició a les Corts de Vilafranca de 1353 (AHCG, I.2.16, f.2r-3r), es mantingué una imposició de la quartera però en els mateixos termes que abans del 1351, fins que el 1365 desaparegué. L'error de Brousolle el porta a dues conclusions també errònies. En primer lloc, la diferència entre el recaptat en un i altre el fa creure que Barcelona realitzava importacions, principalment en farina. I en segon lloc, el fet que la imposició sobre els grans fos molt reduïda i que finalment desaparegués el porta a creure que existia una política municipal destinada a afavorir la importació de grans enfront les importacions de farina. 


\section{4. «PORTAR, PORGAR, MOLDRE O COURE»}

Finalment, abans d'analitzar l'evolució del preu del forment, intentarem avaluar els costos que suposava la transformació del gra en pa.

Amb els quatre conceptes mencionats en el títol es dividien les despeses que la Pia Almoina pagava per a la confecció del pa. Calia en primer lloc transportar el forment des del lloc on es comprava o d'on es rebien les rendes en espècie. El forment a Barcelona es podia adquirir en dos llocs: a la plaça del Blat i al Porxo del Forment al costat del port. Principalment, la Pia Almoina el comprava a la plaça i les despeses eren de $0,5 \mathrm{~d}$. per q.; en canvi si el comprava al Porxo del forment el cost era el doble. Calia també porgar el blat abans de portar-lo a moldre i aquesta despesa pujava a $0,5 \mathrm{~d}$./q.

Normalment, a l'edat mitjana, tant les despeses de mòlta dels grans (dret de moltura) com de cocció per fer el pa (dret de puja) eren una part del gra portat a moldre o de la farina portada a coure. En canvi, a Barcelona, tots dos drets estaven ja a finals del segle XIII monetitzats. Un i altre acostumaven a estar fixats pel costum o per la legislació del lloc determinat però, en el cas de Barcelona, no hem trobat cap referència precisa en les ordinacions conegudes, tot i trobar-se ordinacions que obliguin, per exemple, els moliners a prendre per multura el que era acostumat ${ }^{70}$.

A través dels llibres de comptes de la Pia Almoina, les despeses de cocció del pa queden força clares. El preu era molt estable en el període que hem analitzat: en el primer llibre (1283 i 1284) el preu era de 3,5 d. per quartera de farina; a partir del 1287 i fins al 1324 es mantingué en $4 \mathrm{~d}$./q.; aquest pujà a 4,5 d./q. el 1325 i a 5 d./q. el 1334, preu que es mantingué fins al final de la sèrie analitzada (1345). Cal destacar que les dues últimes pujes coincideixen en el moment de dues fortes crisis.

El valor del dret de moltura és menys clar. Els llibres de comptes dels molins no indiquen mai el preu de moltura ni la quantitat ni el tipus de blat mòlt. A partir de la documentació relacionada amb el molins reials, però, es pot establir el que podríem dir-ne el preu oficial de $6 \mathrm{~d}$./q. preu que cal contrastar amb les despeses de la Pia Almoina ". L'estudi d' aquestes despeses és complicat ja que, a excepció del període 1325-1345, normalment les despeses de moldre

70 Rúbriques de BruniQuer, Ceremonial dels magnifichs Consellers y Regiment de la Ciutat de Barcelona, V vols., Barcelona, 1912-16, vol. V., p. 106. En els llibres de comptes del batlle de Barcelona es mencionen multes a moliners per prendre "més multura que no devia" (Josep CASES HOMS, Llibre del Batlle Reial de Barcelona. Berenguer Morey (1375-78), Barcelona, 1976, pp.40-41.

71 Vegeu P. ORTI, op. cit., p.131-135. Aquí ja havíem utilitzat algun dels llibres de comptes de la Pia Almoina, però ara hem analitzat tota la sèrie. 
van lligades amb unes altres, com les anteriorment mencionades de transport $\mathrm{i}$ porgar; a més, en el conjunt de forment mòlt es podien incloure tant les mòltes a Barcelona com en d'altres llocs, sovint sense indicar-ho. En el període en què les despeses queden desglossades (1334-45), el preu és fix, normalment establert en sacs, que en aquests anys equival a 5 q.; el preu és de $2 \mathrm{~s} .8 \mathrm{~d}$. per sac, que equival a 6,4 d./q.; aquest preu inclou les despeses de mòlta, el transport al molí i la guarda del forment; a partir de notícies disperses, podem desglossar els 6,4 d./q. aproximadament en: 4,8 d. de mòlta, 0,4 d. de guarda i 1,2 d. de transport al molí.

En canvi, entre 1325 i 1330 els preus són variables, anant entre 4 i 5 d. la mòlta (amb transport al molí o sense?) i els $0,4 \mathrm{~d}$. de guarda.

En les èpoques anteriors el problema, com ho hem assenyalat anteriorment, resideix en el fet que les despeses de mòlta van junt amb les de transport del lloc de venda a la Pia Almoina i amb les de porgar. I, sobretot el de transport, podia variar. Tot i això, entre 1287 i 1324, el preus giren al voltant dels 7 i 7,5 d. per q., dels quals es podria distingir el dret de moltura (amb transport al molí i guarda) entre 6 i 6,5 , més al voltant d'1 d./q. de porgar i portar del lloc de venda a la Pia Almoina.

Per tant, les diferències entre els preus de la Pia Almoina i el teòric preu oficial de 6 d./q., que ens donava la documentació sobre els molins, no varia gaire. Això, pel que fa al forment; per a la resta de cereals no tenim cap mena d'informació.

Com a conclusió podem establir que, a part del preu de venda, un comprador barceloní de forment podia pagar per obtenir pa durant la primera meitat del segle XIV, entre 2 i 4 d./q. d'imposició, 0,5 i 1 d./q. de transport, 0,5 d./q. de porgar, 6,4 d./q. de moltura i entre 4 i 5 d./q. de farina per coure. Prenent com a preu mitjà del forment els $8 \mathrm{~s}$./q., els costos de transformar el forment en pa representarien entre el 11,4 i el 14,3\% del preu, més entre el $2,1 \%$ i el 4,2 \% d'imposicions. Això, sense tenir en compte les possibles repercussions que sobre el preu de venda podia exercir el pagament per part del venedor de forment d'imposicions $i$, en el cas de no ser franc de lleuda $i$ mesuratge, de la resta d'impostos reials.

\section{EVOLUCIÓ DEL PREU DEL FORMENT}

\subsection{Moviments interanuals}

Per al coneixement de l'evolució interanual dels preus del forment tenim 
poca informació. Com ja hem dit, a partir dels llibres de comptes de la Pia Almoina només podem datar el període 1291-1296 i el 1337-1342 i, a partir dels llibres de comptes dels molins, el període 1334-36 i 1339.

L'única informació a nivell interanual que podem extreure de tota la sèrie dels llibres de comptes de la Pia Almoina (anys amb compres datables i no datables) són les diferències entre el preu més alt i el més baix, tot i tenint en compte que probablement el preus més alts no apareixen, sobretot a les dues crisis més importants ${ }^{\prime 2}$. Les diferències de preus dins un mateix any poden ser molt fortes: la mitjana de la diferència entre el preu més alt i el més baix de tota la sèrie, a partir de les compres de la Pia Almoina, és del 35,7 \%; però hi ha anys on les oscil lacions poden arribar entre el $50 \mathrm{i}$ el $60 \%$, tot i que en aquesta sèrie falten el preus extrems de les dues crisis més importants. Així la diferència entre la mitjana mensual més alta i la més baixa del 1334 , a partir de les dades dels molins, arriba al $80 \%$.

Aquestes oscil lacions, però, només mostren el punts extrems de cada any. Si agrupem els diferents preus, per exemple, a nivell semestral, el primer que sorprèn és que normalment no acusen la típica pujada de primavera. Tant en el període de 1291-96 com en el de 1334-1342, s'observa que en conjunt el preu del forment és més alt en el semestre juliol-desembre (vegeu quadre 6). Però, si estudiem cada cas, s'observen algunes diferències que es poden explicar en relació amb el tipus de preu mitjà anual: sembla que la pujada típica en el segon trimestre correspon a anys de preus baixos $(1293,1295,1296$ i 1338) i, probablement, als anys de fortes crisis ${ }^{73}$; en canvi, al revés passa, en primer lloc, l'any posterior a un de forta crisi, quan l'evolució anual ve determinada més per la brusca caiguda de preus que per la mateixa evolució anual; en segon lloc, en anys d'escassetat, però que no provoquen una important crisi ${ }^{74}$.

Si analitzem les variacions mensuals, potser ho podrem perfilar una mica millor. En general, ens dóna una apreciació semblant a la de les variacions semestrals, sobretot, si relacionem any per any amb el nivell general de preus. A la mitjana dels dos períodes datables, s'observa clarament aquest fenomen en la dels anys 30 del segle XIV; en canvi, la de 1291-96 és molt més centrada.

72 Com veurem, tant el 1326 com el 1334, en els moments més àlgids de la crisi, la Pia Almoina deixà de servir menjar als pobres.

${ }^{73}$ No tenim datat cap any de forta crisi: de l'any collita 1333-34 només podem datar-ne el segon semestre.

${ }^{74}$ L'existència de preus més alts el primer semestre també s'observa a Florència; apareix també en èpoques de crisi moderada però, en canvi, no s'observa en èpoques de preus baixos (Charles M. de LA RONCIÈRE, Prix et salaires à Florence au XIV' siècle (1280-1380), Roma, 1982 pp. 94-96. 
Quadre 6. Variacions semestrals del preu del forment

\begin{tabular}{|c|c|c|c|c|c|c|c|c|c|c|}
\hline & 1291 & 1292 & 1293 & 1294 & 1295 & 1296 & & & & Mitjana \\
\hline \multirow[t]{2}{*}{$\begin{array}{l}\text { jul-des } \\
\text { gen-ju }\end{array}$} & \begin{tabular}{|c}
121,7 \\
100 \\
91,6 \\
75,3
\end{tabular} & \begin{tabular}{|c|}
101,3 \\
100 \\
85,8 \\
84,7
\end{tabular} & $\begin{array}{c}65,3 \\
100 \\
73,4 \\
112,5\end{array}$ & \begin{tabular}{|c}
73,4 \\
100 \\
66,7 \\
90,8
\end{tabular} & $\begin{array}{c}67,9 \\
100 \\
73 \\
107,5\end{array}$ & $\begin{array}{c}73,4 \\
100 \\
84,7 \\
115,3\end{array}$ & & & & $\begin{array}{c}83,8 \\
100 \\
82,5 \\
98,4\end{array}$ \\
\hline & 1334 & 1335 & 1336 & 1337 & 1338 & 1339 & 1340 & 1341 & 1342 & Mitjana \\
\hline $\begin{array}{l}\text { jul-des } \\
\text { gen-jun }\end{array}$ & \begin{tabular}{|l}
136,1 \\
100 \\
117,9 \\
86,7
\end{tabular} & {$\left[\begin{array}{l}122,1 \\
100 \\
114,5 \\
93,7\end{array}\right.$} & $\mid \begin{array}{l}117,9 \\
100 \\
108 \\
91,6\end{array}$ & $\begin{array}{c}98,1 \\
100 \\
66,2 \\
87,6\end{array}$ & \begin{tabular}{|c}
81,5 \\
100 \\
96,2 \\
118
\end{tabular} & $\begin{array}{c}108,2 \\
100 \\
95,5 \\
66,3\end{array}$ & \begin{tabular}{|l}
104,2 \\
100 \\
92,8 \\
69
\end{tabular} & $\begin{array}{c}91,8 \\
100 \\
86,4 \\
94,2\end{array}$ & $\begin{array}{c}88,8 \\
100 \\
91,8 \\
103,4\end{array}$ & \begin{tabular}{|l}
105,4 \\
100 \\
98,8 \\
93,7
\end{tabular} \\
\hline
\end{tabular}

A partir de l'estudi en detall de cada any en relació al preu mitjà anual podem establir tres tipus:

1. Preus superiors al segon semestre (exemple any 1293-94): els preus es mantenen per sota de la mitjana fins al desembre amb un augment fins l'abril quan el preu ha de baixar per les perspectives d'una nova bona collita o començar a pujar si es preveu una mala anyada.

2. Pujada constant durant l'any: correspondria als anys de forta crisi dels quals no hem pogut datar cap any sencer -només el segon semestre de l'any 1334-, però és problable que s'establís la típica diagonal amb un augment progressiu dels preus.

3. Preus més alts al primer semestre: creiem que poden reflectir dues situacions diferents: en primer lloc, els anys posteriors a una forta crisi, on predomina la caiguda general de preus al llarg de l'any; i, en segon lloc, aquells de crisi controlada, quan aquesta és superada per les importacions. Corresponen a aquest tipus la situació de la majoria dels anys de la dècada dels 30 que coneixem $\mathrm{i}$ en aquest es barregen tots dos factors: caiguda de preus després del 1334, malgrat mantenir-se a Catalunya les males anyades. D'aquests anys, a més, podem comparar l'evolució del preu amb la dels ingressos dels molins que són un reflex del volum de consum de gra a la ciutat. En general, i com és lògic, la tendència dels ingressos dels molins és inversa a la dels preus. Tenint en compte que les dades són molt precàries, ja que només es poden reconstruir dos anys-collita, s'observa, en primer lloc, un equilibri a nivell de mitjana semestral, però a nivell mensual s'observen clares diferències entre tots dos semestres. El primer ve caracteritzat per un període juliol-setembre amb els mínims anuals, seguit d'octubre-desembre amb els màxims: això concorda amb els 
Quadre 7. Mitjanes mensuals del preu del forment"

\begin{tabular}{|c|c|c|c|c|c|c|c|c|c|c|c|}
\hline & 1291 & 1292 & 1293 & 1294 & 1295 & 1296 & & & & & Mitjana \\
\hline $\begin{array}{l}\mathrm{jl} \\
\mathrm{ag} \\
\mathrm{s} \\
\mathrm{o} \\
\mathrm{n} \\
\mathrm{d} \\
\mathrm{g} \\
\mathrm{f} \\
\mathrm{m} \\
\mathrm{a} \\
\mathrm{mg} \\
\mathrm{jy}\end{array}$ & \begin{tabular}{|l}
122,7 \\
121,4 \\
113,3 \\
121,8 \\
124 \\
126,9 \\
119,2 \\
118,5 \\
120,5 \\
116,7 \\
86 \\
107,7
\end{tabular} & $\begin{array}{c}101,1 \\
\\
99,3 \\
106 \\
102 \\
99,2 \\
104,5 \\
96,7 \\
83,9 \\
72,5 \\
71,5\end{array}$ & $\begin{array}{l}65 \\
63,9 \\
63 \\
62,7 \\
71,7 \\
76,5 \\
76,7 \\
74,5 \\
70 \\
69,5\end{array}$ & $\begin{array}{l}76,5 \\
74,6 \\
72,7 \\
69,8 \\
72 \\
65,8 \\
66 \\
68,5 \\
61\end{array}$ & $\begin{array}{l}67 \\
62 \\
66 \\
62 \\
73 \\
77,3 \\
72 \\
70 \\
77 \\
84 \\
70 \\
65\end{array}$ & $\begin{array}{l}64 \\
72 \\
75 \\
78 \\
78 \\
79 \\
87 \\
88 \\
78,7\end{array}$ & & & & & $\begin{array}{l}83,8 \\
80,9 \\
85 \\
83,4 \\
84,9 \\
.90,6 \\
87,2 \\
85,8 \\
85 \\
82 \\
74,2 \\
77,9\end{array}$ \\
\hline & 1333 & 1334 & 1335 & 1336 & 1337 & 1338 & 1339 & 1340 & 1341 & 1342 & Mitjana \\
\hline $\begin{array}{l}\mathrm{jl} \\
\mathrm{ag} \\
\mathrm{s} \\
\mathrm{o} \\
\mathrm{n} \\
\mathrm{d} \\
\mathrm{g} \\
\mathrm{f} \\
\mathrm{m} \\
\mathrm{a} \\
\mathrm{mg} \\
\mathrm{jy}\end{array}$ & \begin{tabular}{|l}
222,3 \\
234 \\
297 \\
248,4 \\
222,3 \\
165,6
\end{tabular} & $\begin{array}{l}138,6 \\
141,3 \\
140,4 \\
137,7 \\
126,9 \\
131,4 \\
126,9 \\
102,6 \\
119,7 \\
122,4 \\
123,3 \\
112,5\end{array}$ & $\begin{array}{l}117,9 \\
135,9 \\
119,7 \\
120,6 \\
111,6 \\
126,9 \\
126 \\
126 \\
118,8 \\
108 \\
101,7 \\
106,2\end{array}$ & $\begin{array}{l}120,6 \\
126,9 \\
129,6 \\
113,4 \\
108,9 \\
108\end{array}$ & $\begin{array}{c}90 \\
106,5 \\
99 \\
97 \\
90 \\
\\
88 \\
78 \\
87,5 \\
87,3\end{array}$ & $\begin{array}{l}82 \\
79,3 \\
79,5 \\
85 \\
92,7 \\
91,8 \\
95,4 \\
99 \\
99 \\
99\end{array}$ & $\begin{array}{l}99 \\
99 \\
107,1 \\
109,8 \\
117 \\
117\end{array}$ & $\begin{array}{r}87 \\
95 \\
108 \\
121 \\
110\end{array}$ & $\begin{array}{l}99 \\
88 \\
88,3 \\
82 \\
82 \\
82 \\
\\
95 \\
91\end{array}$ & $\begin{array}{l}90 \\
86 \\
90 \\
89 \\
89 \\
91 \\
96 \\
91\end{array}$ & $\begin{array}{r}103,1 \\
111,2 \\
111,9 \\
111,5 \\
105,5 \\
107,9 \\
101,1 \\
98,7 \\
98,9 \\
98,2 \\
100,1 \\
97,5\end{array}$ \\
\hline
\end{tabular}

15 La segona mitjana ha estat calculada per al període 1334-1342; no s'hi ha inclòs l'any 1333, perquè en ésser incomplet $\mathrm{i}$ amb uns preus tant alts es desvirtua la mitjana. 
preus, però a l'inversa: hem vist com l'any collita comença amb els preus més alts i no baixa fins a l'hivern, moment de màxima producció dels molins. Recordem que parlem d'anys dolents encara que no crítics; per tant, sembla que el preu del forment esperava baixar més per les perspectives d'una bona possibilitat d'importació que no pas de la producció. El segon semestre es caracteritza per un major equilibri amb un cert augment de la producció els últims mesos, probablement, per un augment del consum de blat per la «soldadura», però que no provocava una alça de preus almenys en comparació amb els del principi d'any.

Gràfic 3. Preus mensuals mitjans del forment (núm. índex) ${ }^{76}$
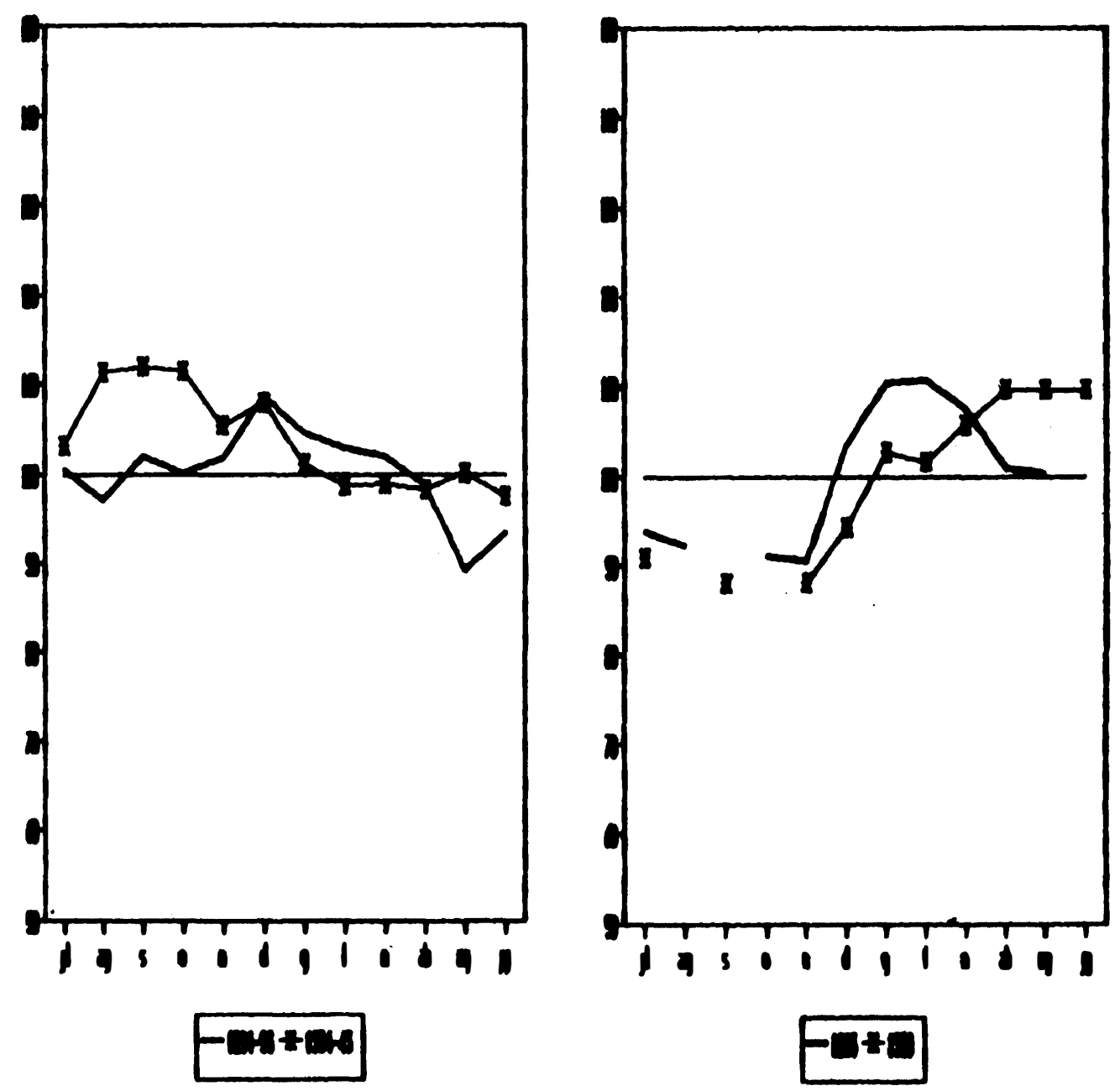

${ }^{76}$ El primer gràfic correspon a la mitjana dels dos períodes datables; el segon, a dos exemples d'anys amb augment de preus al segon semestre; i el tercer, a la comparació del preu del forment $\mathrm{i}$ dels ingressos dels molins. En tots els casos, $100=$ al valor de la mitjana. 


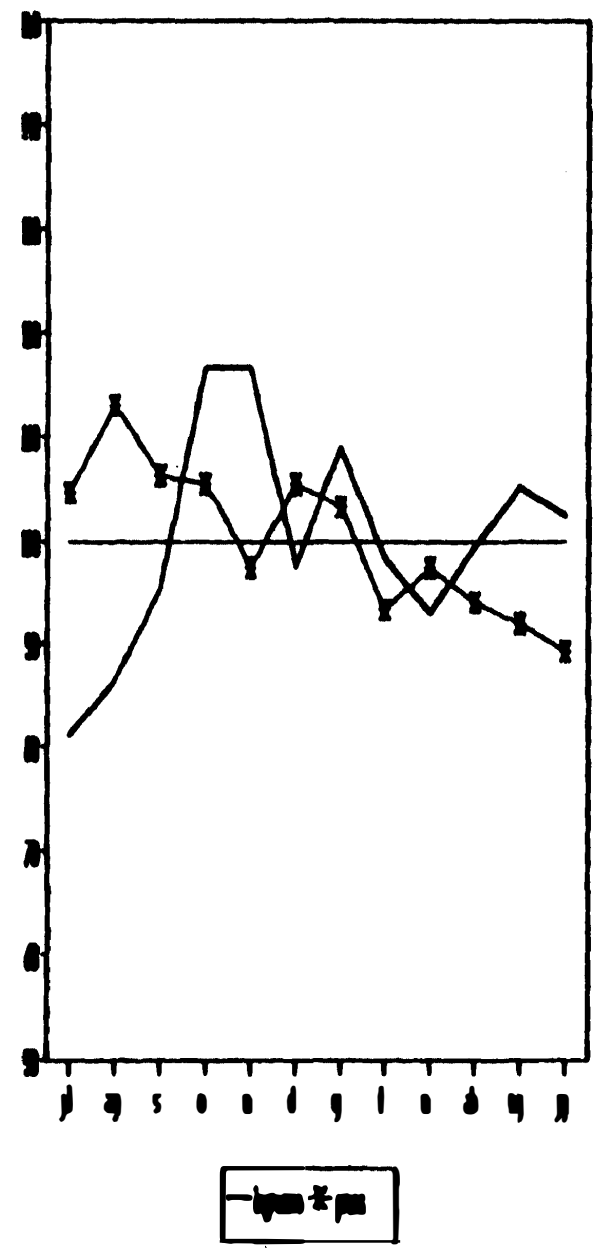

Per tant, sembla que la tendència del preu dins un any venia donada per dos factors: en primer lloc, per la bona o mala collita que determina el preu inicial de l'any-collita $i$, en segon lloc, en el cas d'una mala anyada, la tendència del preu variava segons les possibilitats d'importació, fet que provocava en cas positiu, una reducció del preu durant el segon semestre.

\subsection{Moviments generals}

Les caresties frumentàries medievals varen estar condicionades, a tot l'Occident, per un augment de les demandes de cereals motivada, a partir de la segona meitat del segle XI, pel creixement demogràfic i per la progressiva conversió del pa com l'element bàsic de l'alimentació de les classes populars, 
procés al qual es va respondre amb un creixement extensiu de les àrees conreades i que trobà els seus límits vers el 1250. Davant el fre del creixement econòmic, els senyors reaccionaren amb un augment de la seva pressió, fet que accentuà el precari equilibri de l'economia pagesa, que es convertí en molt més fràgil davant les inclemències climàtiques. Malgrat que el desenvolupament del comerç de blats pogué atenuar les males anyades regionals, sobretot en l'àmbit urbà, era un comerç inestable, i en molts moments facilità també la internacionalització de les crisis. Aquestes s'anaren repetint durant el XIV cada cop més freqüentment $\mathrm{i}$ cada cop amb més virulència ".

La Corona d'Aragó no escapà a aquest procés. Sembla que durant el segle XIII es convertí en un estat excedentari a partir de la colonització interior i la repoblació del regne de València: els blats occidentals i meridionals cobrien, així, el dèficit endèmic de la franja litoral. Això no vol dir que no hi hagués caresties, però, potser a excepció de 1218 i 1227, només foren escassetats generalitzades o dificultats regionals ${ }^{78}$. Davant la manca de cereals, es cercaven a Sicilia, Sardenya, Berberia, Provença i Castella ${ }^{79}$. Caldrà arribar a finals de la dècada dels 70 i principis dels 80 perquè el sistema entri en la seva primera crisi important no tan sols derivada de les males collites sinó també de les disfuncions provocades en el mercat interior per la bel-ligerància d'un sector de la noblesa davant l'enfortiment del poder reial i pel gran conflicte internacional de la guerra de Sicília, que actua en dos sentits, alterant els circuits comercials i amb un augment de la pressió fiscal ${ }^{80}$.

Dins d'aquest marc i a partir de les dues últimes dècades del dos-cents, apareixen les primeres sèries de preus de Barcelona que hem analitzat. Intentarem resseguir l'evolució d'aquests preus entre 1283 i 1345, o sia, entre les primeres manifestacions de deficiències greus fins a les portes del primer brot de pesta important.

72.

"Un estat de la qüestió amb la bibliografia corresponent: A. RIERA, op. cit., pp. 35-

${ }^{7}$ Ibidem, pp. 57-68.

79 Sobre l'origen dels cereals importats per Barcelona, vegeu: Josefa MUTGÉ VIVES, $L a$ ciudad de Barcelona durante el reinado de Alfonso el Benigno (1327-1336), Barcelona, 1987, pp. 41-95; ídem, Trigo sardo en Barcelona durante el reinado de Alfonso el Benigno, "VIII Congrés d'Història de la Corona d'Aragóm, València, 1973, vol. II, pp. 235-241; Sebastià RIERA I VIADER, El proveïment de cereals durant la crisi del "mal any primer», "II Congrés d'Història del Pla de Barcelona» (1985), Barcelona, 1989, vol. I, pp. 315-326; Eva SERRA, op. cit., pp. 72-78.

${ }^{80}$ A. RIERA, op. cit., pp. 61. 
Quadre 8. Mitjanes anuals del preu de la quartera de forment a partir dels llibres de comptes de la Pia Almoina (en diners)

\begin{tabular}{|c|r|c|r|c|r|c|r|r|r|}
\hline Any & Preu & Any & Preu & Any & Preu & Any & Preu & Any & Preu \\
\hline 1283 & 85,5 & 1298 & 81,3 & 1311 & 111,7 & 1322 & 104,4 & 1335 & 126,1 \\
1284 & 106,8 & 1299 & 60 & 1312 & 97,3 & 1323 & 110,9 & 1336 & 109,4 \\
1287 & 86,6 & 1300 & 90,6 & 1313 & 114,2 & 1324 & 117,3 & 1337 & 96,7 \\
1288 & 77,6 & 1301 & 90,9 & 1314 & 94,1 & 1325 & 127,2 & 1338 & 85,1 \\
1291 & 120,3 & 1302 & 99,1 & 1315 & 86,5 & 1326 & 105,5 & 1339 & 96,5 \\
1292 & 96,6 & 1304 & 95,5 & 1316 & 87,4 & 1329 & 100,9 & 1340 & 107,1 \\
1293 & 69,2 & 1305 & 87,7 & 1317 & 98,9 & 1330 & 98,2 & 1341 & 88,5 \\
1294 & 69,9 & 1306 & 99,2 & 1318 & 96,4 & 1331 & 99,8 & 1342 & 91,1 \\
1295 & 69,8 & 1307 & 88,4 & 1319 & 98,6 & 1332 & 109,8 & 1345 & 108,7 \\
1296 & 75 & 1308 & 73,6 & 1320 & 89,4 & 1333 & 134,1 & & \\
1297 & 89,6 & 1309 & 109,8 & 1321 & 93,4 & 1334 & 137,5 & & \\
\hline
\end{tabular}


Gràfic 4. Evolució del preu del forment a partir de les compres de forment de la Pia Almoina, 1283-1345 (en diners)

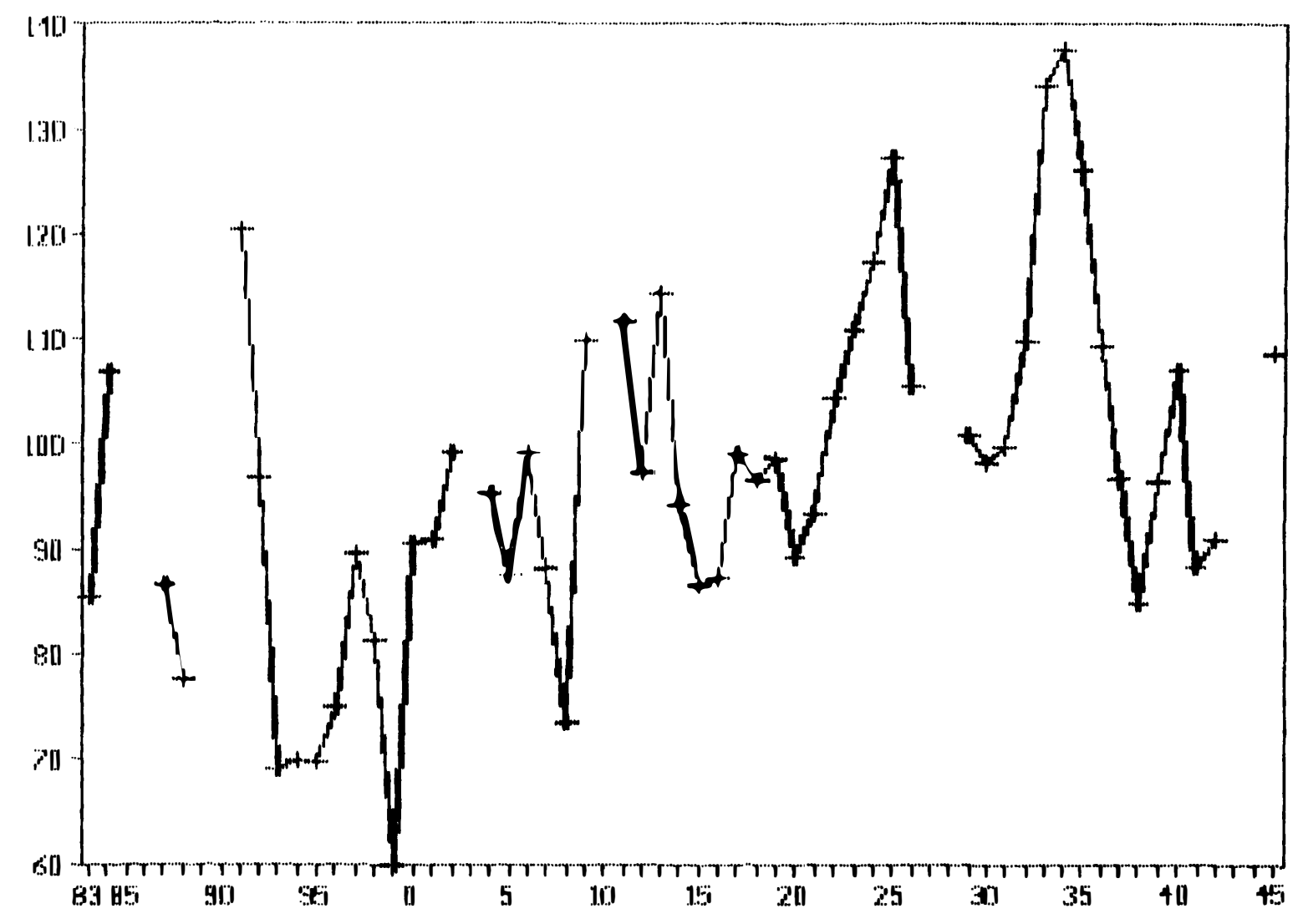

Les dades anteriors al 1291 són molt fragmentàries. Per als anys 70 només tenim dues úniques referències: una del $1272 \mathrm{i}$ una altra del $1273 \mathrm{amb}$ preus de 7 i 6 s. per quartera, respectivament ${ }^{81}$. Per a la dècada dels 80 , a part dels preus de les compres de la Pia Almoina (quadre 8), tenim les primeres referències dels llibres de comptes del batlle general de Catalunya que ens dóna

${ }^{81}$ ACA, C., reg. 19, f.1v-3v. És la primera menció de l'assignació d'una quantitat de forment diària sobre les rendes dels molins reials de Barcelona. Concretament, 2 quartans de forment diaris a un pintor «ad opus comestionis domus sue», que foren pagats el 1272 a raó de 7 s./q. i el 1273 a raó de 6 s./q. 
una mitjana anual de 9 s. 3 d./q., el 1286, i de 7 s. 10,5 d., el $1288^{82}$. En canvi, a partir del 1291, la sèrie de la Pia Almoina ja és pràcticament contínua fins al 1345, i ens mostra per a la dècada dels 90 uns preus molts alts per als anys 1291 i 1292 , seguits dels tres anys amb els preus més baixos de la sèrie, tendència que s'invertirà a partir del 1296. Per tant, el període centrat entre 1270 i 1295 vindria marcat almenys amb dues crisis importants: una entre 1284-86 i una altra entre 1291 i 1292 . Però, probablement, a diferència del període posterior, en els anys següents a les crisis es recuperaven els preus anteriors: els de 1272 i 1273 són comparables als de 1293-95. Per tant, seria a partir del 1298 que començaria un procés d'alça contínua del preu del forment, alça que s'allargaria fins a la crisi del «mal any primer». De les dues caresties importants d'aquest període, la primera sembla una crisi de caire més general, ja que també s'observa a Itàlia, a la França oriental, al Llenguadoc, a Castella i a Navarra; mentre que la segona sembla més de caire regional ${ }^{83}$.

Aquestes crisis no es poden deslligar dels conflictes bèl - lics ocasionats per la conquesta de Sicília: tant pels possibles problemes de subministrament a la ciutat provocats per la guerra, com per la pressió fiscal que generaren els conflictes. La dècada dels anys 80 se'ns presenta com el prefaci d'una sèrie de problemes i solucions que caracteritzaran el segle XIV: la política expansionista de la Corona d'Aragó a la Mediterrània provocà els primers enfrontaments seriosos internacionals; les necessitats financeres de la corona generades per la guerra causen un important procés d'alienació del patrimoni reial malgrat les prohibicions de les corts de Montsó del 1289; les del 1283 ens apareixen per primer cop amb l'organització i els continguts que li seran pròpis en segles posteriors ${ }^{84}$; a nivell fiscal s'acorden els primers subsidis de Corts a les de Montsó de 1289 i les de Barcelona de 1291. I encara més pel que fa a Barcelona, amb la concessió del famós privilegi del 1284 ( «Recognoverum proceres») i, quant a la fiscalitat, amb la menció de la primera cisa municipal el $1287^{85}$ i amb l'enfranquiment de questia del 1299, pagat amb els deutes acumulats per Pere II i Alfons II ${ }^{86}$. Eren concessions de la monarquia que

${ }^{82}$ Montserrat SANMARTí I ROSET, El llibre de comptes de Romeu Gerard (1286-1289), Batlle General del rei Alfons III d'Aragó i Catalunya, tesi doctoral inèdita, Barcelona, 1978, pp.80-81 i 240-242. Parma.

${ }^{83}$ A. RIERA, op. cit., pp.70-71. Entre 1290 i 1292 només s'observen penúries a Pisa i

${ }^{84}$ José Luis MARTín, Privilegios y cartas de libertad en la Corona de Aragón (12831289), dins Economía y sociedad en los reinos bispànicos de la baja Edad Media, vol.I, pp.220235.

8s A. ARAGÓ; M. Costa, op. cit., doc.31, pp.20-21.

${ }^{86}$ AHCB, Llibre Vermell, vol.I, f.1r-2r. 
afavorien principalment una élite de ciutadans de Barcelona ja en aquesta època clarament rendista. A més, cal considerar els costos econòmics que aquestes concessions significaren per als ciutadans de Barcelona a través de les gravoses ajudes ${ }^{87}$. Tot això, crisi frumentària, pressió fiscal, beneficis d'un grup social de Barcelona cada cop més poderós, poden ser elements per a explicar la coneguda revolta de Berenguer Oller ${ }^{88}$.

Com assenyalàvem anteriorment, després del període 1293-97, anys amb preus molt baixos (mitjanes anuals que arriben a baixar per sota dels $6 \mathrm{~s}$./q.), comença una etapa caracteritzada principalment per l'alça continuada dels preus del forment, almenys fins a la crisi del «mal any primer». Encara era una època de fort creixement per a la ciutat malgrat que es comencin a mostrar el primers signes de la crisi, principalment amb aquest rescalfament continu dels preus dels blats. Uns altres índexs econòmics que ens poden mostrar aquest creixement són, per exemple, els mateixos molins de Barcelona, en dos aspectes: en primer lloc, es continuaren construint nous molins: el casal del Clot Sobirà, el 1303-4 ${ }^{89}$, i els cinc casals petits de Bonanat Sapera, el $1330{ }^{90}$; en segon lloc, el preu de l'arrendament del conjunt dels molins reials de Barcelona augmentà durant els primers 40 anys del tres-cents ${ }^{\circ 1}$.

Com indicàvem al principi, les dades que ens aporta la Pia Almoina entre 1298 i 1313 són les menys fiables perquè corresponen al període en què la Pia

87 Amb la provisionalitat que cal tractar aquest tema, Barcelona pagà a finals del segle XIII almenys les següents questies: 80.000 s. el 1276 (ACA, C, reg.20 f.350v), 80.000 s. el 1281 (ídem, reg. 51 f. 2r), 160.000 s. el 1284 (ídem, reg. 51, f.6r) 100.000 s. el 1292 (ídem, reg.82, f.117v-119v); a més, a les Corts de Montsó de 1289 s'aprovà un subsidi per 3 anys (AHCB, Llibre Vermell, vol.II, f.101v-102v); el 1292 es concedí una cisa a Catalunya de duració de dos anys (ACA, Consell de Cent, perg.2 i 336; A. ARAGó; M. CosTA, op. cit., doc.42 i 43); finalment, el 1299 Barcelona aconseguí la franquesa de questia després de perdonar a Jaume II 250.000 s. i 2.000 dobles d'or que la corona devia des del temps de Pere II i Alfons II (AHCB, Llibre Vermell, vol.I, f. 1r-2r, citat per: F. CARRERAS CANDI, op. cit., p. 633).

${ }^{88}$ Carme BATlle I GallaRT, Aportacions a la bistòria d'una revolta popular: Barcelona 1285, "Estudis d'Història Medieval», II (1970), pp.19-29; Philippe WolfF, L'épisode de Berenguer Oller à Barcelone en 1285. Essai d'interpretátion sociale, "Anuario de Estudios Medievales", 5 (1968), pp.207-222.

89 Lluïsa CASESA; Mariona FAGES; Bernat GÓMEZ; Montse RIUS, El nou casal dels molins del Clot: un exemple de patrimoni reial al començament del segle XIV, «Finestrelles», 2 (1990), pp.113-127; P. ORTI, op. cit., pp.66-79.

90 P. ORTI, La construcció i l'explotació dels molins del Rec Comtal de Barcelona al segle XIV: els casals dits de Bonanat Sapera, «Ier. Col-loqui d'història de l'alimentació a la Corona d'Aragón, Lleida, 1990, en premsa.

${ }_{91}$ Es passà dels 20.000 s. a principis del segle XIV a 23-24.000 s. els anys 20 (P. ORTI, op. cit., p.188). 
Almoina fa menys compres. Fins al 1316 les variacions entre un any $i$ un altre poden ser fortes i és difícil marcar uns cicles clars. Tot i això, es pot distingir un primer cicle entre 1298 i 1308, amb la punta de preus més alts concentrats entre 1302 i 1306, que coincideix amb notícies de males anyades a Mallorca, a Navarra, a Castella, al Midi i a Itàlia ${ }^{92}$. Un segon cicle entre 1308 i 1315 amb preus més alts el 1309, 1311 i 1313, que també coincideix amb diverses notícies sobre dificultats a València, a Mallorca, a Terol, a Navarra, a Castella, a Florència, a Palerm i fins i tot al Magrib, que porta a Agustín Rubio a parlar d'una possible crisi general a l'àrea mediterrània ${ }^{93}$.

Vindria després un període de relativa tranquil-litat entre $1316 \mathrm{i}$ 1320 , just en el moment de la crisi important al nord d'Europa ${ }^{94}$. Posteriorment ens trobem amb dos cicles clarament definits, centrats en dues crisis importants: la del 1325-26 i la del 1333-34. La diferència entre aquestes crisis $\mathrm{i}$ les anteriors torna a ser igual al que hem vist per a la dècada dels anys 80 del segle XIII: mentre que durant el primers 20 anys del segle XIV hi hagué una relativa calma en els conflictes mediterranis, cosa que provocà també una reducció de la pressió fiscal, les crisis encara que generals foren menys fortes; en canvi, entre 1320 i 1340 , es tornen a conjuminar la guerra i la pressió fiscal amb un preu del forment que no ha parat de pujar des dels inicis del segle.

La crisi dels anys 20, que assoleix el seu punt àlgid l'any collita del 1325-26, va tenir, probablement, una virulència semblant a la del 133334. L'actitud de la Pia Almoina en ambdós casos fou idèntica: mentre que fins aleshores havia anat comprant forment i servint pa als pobres, malgrat les males anyades, tant el 1325 com el 1334 la Pia Almoina deixà de servir menjar, i assignà a canvi una quantitat de diners a cada pobre "s. Això fa que

92 Maurice BERTHE, Famines et épidémies dans les campagnes navarraises à la fin $d u$ Moyen Age, París, 1984, vol.I, pp.207-210.

93. Agustín RUBIO VelA, Crisis agrarias y carestías en las primeras décadas del siglo XIV. El caso de Valencia, «Saitabi», XXXVII (1987) pp.135-139.

94 Vegeu, entre d'altres, Ian KERSHAW, The Great Famine and Agrarian Crisi in England 1315-1322, «Past and Present», 59 (maig 1973), pp.3-50;

9s Sembla que el motiu principal del fet que la Pia Almoina deixés de servir menjar el 18 de febrer de 1326 fou de tipus social, encara que l'única referència és la que dóna el llibre de comptes: «Dimarts que comença la persequció dels clergues e ns gitaren de la ciutat...» (ACB, PA-1325-D, f.39v); en principi, havia de donar a canvi una quantitat de diners a cada pobre, però durant el mes de febrer no es féu ni això. A partir de l' 1 de març, es pagaren $4 \mathrm{~d}$. per pobre, fet que ens permet conèixer que la Pia Almoina alimentava entre 190 i 200 pobres. No es tornà a servir menjar regularment fins el 2 d'agost de 1326. Aventurar una hipòtesi del que succeía partir d'aquestes dades és pràcticament impossible: sembla que, per algun conflicte, hi hagué una persecució de clergues que paralitzà la Pia Almoina fins a finals de febrer i, posteriorment, podia haver deixat de donar menjar per la crisi, igual que passà el 1334. 
els preus mitjans anuals, calculats a partir de les compres de la Pia Almoina, no reflecteixin l'amplitud global de la crisi; però, mentre que per al 1334 tenim la mitjana anual a partir de les dades dels molins reials de Barcelona, per al 1325 no en tenim; per tant, en aquest sentit, no les podem comparar.

Com assenyalàvem anteriorment, aquesta crisi no es pot deslligar dels problemes derivats de la conquesta de Sardenya. Sembla que la crisi afectà també València, però no tingué un abast molt gran; només hi ha notícies de males anyades al Magrib *. Però, la mateixa conquesta de Sardenya hagué de provocar dificultats per aprovisionar-se de cereals de l'illa, per les mateixes destrosses de la guerra i pel subministrament dels exèrcits. A més, la participació més o menys encoberta de Gènova provocà dificultats d'aprovisionar-se a Sicilia. "

Pel que fa a la pressió fiscal, ja hem vist com des del 1314 tornen a ser freqüents les imposicions sobre la compra-venda de productes a la ciutat, entre les quals sempre n'hi havia una que gravava els cereals. Aquestes es convertiren quasi en anuals durant els anys 20 i, a més, s'establí un impost directe sobre les persones i els seus béns, aprovat a les Corts de Barcelona de $1323^{98}$.

Les dificultats que s'observen a València el 1328-29 i que afectaren una gran part de l'Europa meridional, sembla que no tingueren greus conseqüències per a Barcelona ${ }^{9 \%}$. Tot i que no tenim cap dada per als anys $1327 \mathrm{i} 1328$, el preu mitjà del 1329 no reflecteix cap crisi important: és un preu una mica alt, però si hi hagués hagut una crisi seriosa, se n'hauria ressentit més. Sembla que la tendència dels preus fou d'una progressiva reducció a partir del 1325-26 fins al 1330 , quan començà un altre cop a pujar fins al màxim l'any-collita del 1333-34.

Malgrat els treballs sobre la crisi del «mal any primer» ${ }^{100}$, manca encara

${ }^{6}$ A. RUBio, op. cit., p. 141.

"7 Marina MITJÀ, Barcelona y el problema sardo en el siglo XIV, "VI Congreso de Historia de la Corona de Aragón» (1957), Madrid, 1959, pp.449-450.

${ }^{98}$ AHCB, Llibre vermell, v.I, f.15v-21v, 3.11 .1323 (citat per Francesch CARRERAS CANDI, La ciutat de Barcelona, "Geografia General de Catalunya", Barcelona, s/d, vol.I p.634. Barcelona pagà a més el $1321,300.000$ s., 200.000 s. el 1326 i 100.000 s. el 1328.

9) A. RUBio, op. cit., p.143-146.

${ }^{100}$ Entre el últims citem: Josefa MUTGÉ, Trigo sardo en Barcelona durante el reinado de Alfonso el Benigno, "VIII Congrés d'Història de la Corona d'Aragó», vol.II, València, 1972, p.235-241; Sebastià RIERA VIADER, El mal any primer a Barcelona: una crisi de subsistències a la Baixa Edat Mitjana, tesi de llicenciatura, UAB, 1979; ídem, El proveïment de cereals durant el mal any primer (1333), "II Congrés d'Història del Pla de Barcelona", Barcelona, 1989, vol.I, p.31 5-32.6; Agustín RUBIO VelA, A propósito del "mal any primer». Dificultades cerealísticas en la Corona de Aragón en los años treinta del siglo XIV, «Estudios dedicados a J. 
una monografia sòlida sobre aquesta crisi de subsistència. Sense desmerèixer la importància d'aquesta crisi, cada cop sembla més dubtós el fet de que fos el primer mal any, entès com el primer gran símptoma de la depressió baixmedieval perquè, com hem vist, les dificultats se'ns mostren des de molt abans ${ }^{101}$. Per tant, potser caldria situar-la com la primera gran crisi dins el conjunt d'unes dificultats que es comencen a observar al final del segle XIII.

Les dades dels preus i dels ingressos dels molins ens ofereixen informacions interessants sobre aquesta crisi, la més documentada de totes les que hem analitzat, ja que podem contrastar l'evolució dels preus entre la Pia Almoina i els molins $i$, a més, comparar-les amb els ingressos dels molins dels quals, com ja hem indicat, només posseïm dades per als anys 1334,35, 36 i 39 .(quadre 9).

Com indicàvem, sembla que la tendència a la baixa dels preus del forment a partir de la crisi de 1325-26 canvià a partir del 1330, però els primers indicis de males collites aparegueren el 1332 i inauguraren una època de quatre anys que, probablement en el cas de Barcelona, van ser motivades per una sequera ${ }^{102}$. Els moments més crítics es centraren en l'any-collita 1333-34, sobretot entre desembre ${ }^{103}$ i març, mes on s'arribà a una mitjana mensual de 27 s./q. i $\mathrm{amb}$ possibles preus puntuals entre $30 \mathrm{i} 40 \mathrm{~s}$./q. ${ }^{104}$. Es també el moment que la Pia Almoina deixà de servir menjar als pobres des del 17 de gener fins al 15 de

Peset Aleixandre», València, 1982, vol.III, p.475-487; Max TURULL I RUBINAT, El «mal any primer» a Cervera: trasbals socio-polític $i$ crisis de subsistències (1333), "Miscel lània Cerverina», vol.IV, 1986, p.23-54. Aquests treballs recullen la bibliografia anterior.

101 A. RUBIO, Crisis agrarias y carestias, pp.133-134.

102 Davant les queixes presentades pels propietaris de molins de Barcelona per la construcció dels casals de Bonanat Sapera, aquest envià una carta el desembre de 1338 als consellers de Barcelona, com a representants de l'Hospital d'en Pere Desvilar, un dels propietaris de molins, explicant els beneficis aportats a la ciutat pels nous molins i, entre altres coses, ens diu: «E pot-se dir ab veritat que si per les dites obres fetes en la dita resclosa e en lo dit Rech no ych fos, no ych agra entrada la meytat de la aygua que hic és entrada en ten grans seccades com hi ha haüdes" (AHCB, Consell de Cent, XIII-6, f. $115 v-116 v$ ); i més endavant: «... depuys que la fam e carestia fo passada e la terra fo en cominal estament de blat, ço és, de II anys ençà que fo finits per tot juny prop passat..." (ídem, f.116v).

${ }^{103}$ De l'any 1333 només tenim notícia de la mitjana anual i d'algun preu: el 23 de juny es pagaven 15 s./q. (AHCB, Consell de Cent, I-XII, f.69v), al novembre 20 s./q. (ídem, I-XIII, f.26v) i, el 29 de desembre, de 25 a 26 s./q. (ídem, I-XIII, f.47r); vegeu: Josefa MUTGÉ VIVES, La ciudad de Barcelona durante el reinado de Alfonso el Benigno (1327-1336), Barcelona, 1987, pp.82-83.

104 S'arribà a 30 s. el 15 i 23 de febrer (AHCB, Consell de Cent, I-XIII, f.57r i 61v) i a 40 s. el 16 d'abril (idem, f.75v-76r); vegeu: ibidem, pp.83-84. 
maig ${ }^{105}$. A partir, però, del més de juny els preus cauen en picat $i$ es redueixen a l'estiu a la meitat (vegeu quadre 7).

Quadre 9. Evolució del preu d'una quartera de forment a partir dels llibres de comptes del batlle general de Catalunya (en diners)

\begin{tabular}{|c|r|r|r|r|r|}
\hline ANY & \multicolumn{1}{|c|}{ PREU } & ANY & PREU & ANY & PREU \\
\hline & & & & & \\
1301 & 92,2 & 1331 & 107,1 & 1337 & 103,5 \\
1318 & 102,6 & 1332 & 95,4 & 1339 & 102,6 \\
1322 & 102,6 & 1333 & 143,1 & 1340 & 104,4 \\
1326 & 110,7 & 1334 & 197,1 & 1341 & 98,1 \\
1329 & 110,7 & 1335 & 119,7 & 1342 & 94,5 \\
1330 & 95,4 & 1336 & 116,1 & & \\
\hline
\end{tabular}

En general, es pot observar una relació inversa entre els ingressos dels molins $i$ els preus del forment (vegeu gràfic 5). Les primeres dades que en tenim són del gener de 1334 i són els més baixos coneguts. Malgrat que, en conjunt, l'any 1334 és el d'ingressos més baixos, els mesos d'abril-maig s'aconseguiren els màxims dels mesos coneguts, quan suposem que entraren importants càrregues de blat importat ${ }^{106}$. És curiós detectar que precisament el 15 d'abril, quan veiem que ja hi havia blat a Barcelona però el preu no havia baixat, fou quan esclatà la revolta contra els consellers de la ciutat ${ }^{101}$. Entre juny i agost tornaren a baixar, encara que no als nivells de gener-març, i a partir d'aquest moment anaren augmentant gradualment fins al desembre de 1336 , mentre que el preu del forment anà reduint-se. Aquesta tendència continuà fins el 1338, amb una mitjana anual que no es veia des de 1315 i 1316. En canvi, en els any-collita 1339-40 i 1340-41 es torna a detectar alguna dificultat sense comparació amb la crisi del mal any primer.

105 El 17 de gener: «cessavit Elemosina dare panem pauperibus, carn e vi» (ACB, PA-1333-D); igual com el 1326, s'assignaren $4 \mathrm{~d}$. per pobre i aquí a vegades es desglossa $2 \mathrm{~d}$. per pa, $1 \mathrm{~d}$. per peix i $1 \mathrm{~d}$. per faves, i no sempre es paguen totes. En aquest cas la variació del nombre de pobres era més gran des de 200 a 300 pobres.

106 Sebastià Riera ha comptabilitzat almenys sis ambaixades de la ciutat de Barcelona per a resoldre la crisi entre els mesos de gener i febrer de 1334, les quals devien concentrar-se en l'arribada de grans a l'abril (S. RIERA, op. cit., p.322-323).

${ }^{107}$ Carme BATLle I GALlarT, La crisis social y económica de Barcelona a mediados del siglo XV, vol. I, pp.44-52. 
Gràfic 5. Evolució del preu d'una quartera de forment a partir dels llibres de comptes del batlle general de Catalunya

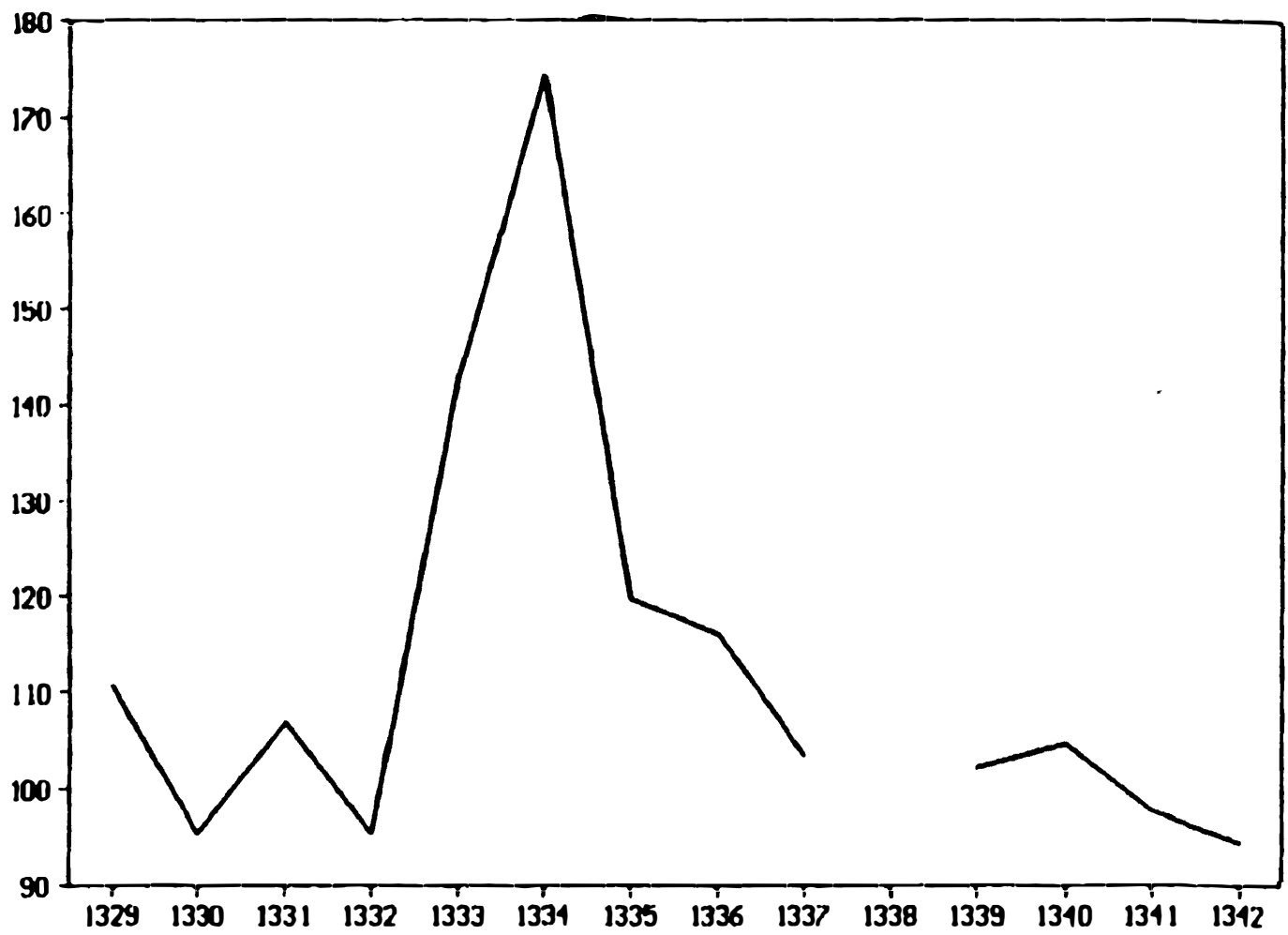

Com assenya làvem, aquesta crisi també anà acompanyada de problemes a la Mediterrània, amb la guerra contra Gènova portada per Barcelona i pel regne de Mallorca, amb atacs dels genovesos precisament contra naus catalanes carregades de blat procedent de Sicilia ${ }^{108}$. I també es traduí en una nova pressió fiscal a Barcelona, centrada a partir del 1330 en un augment de les imposicions sobre la compra-venda de productes, augment en dos sentits: en primer lloc, en el nombre de productes subjectes a imposició, i amb l'augment dels impostos el doble del seu valor anterior. En principi, l'armada fou organitzada i finançada únicament per Barcelona: mentrestant, Alfons III organitzava la campanya contra Granada amb la consegüent recollida de subsidis ${ }^{109}$. Però, precisament

108 Josefa MUTGÉ VIVES, El consell de Barcelona en la guerra catalano-aragonesa, durante el reinado de Alfonso el Benigno, "Anuario de Estudios medievales», 2 (1965), p.244.

109 Manuel SÁNCHEZ MARTÍNEZ, "Questie» y subsidios en Cataluña durante el primer tercio del siglo XIV: el subsidio para la cruzada de Granadina (1329-1334), "Cuadernos de Historia Económica de Cataluña», XVI (1977), pp. 11-54. 
el 1333, a les Corts de Montblanc les ciutats i viles reials de Catalunya concediren una ajuda de $10.000 \mathrm{l}$. per a la guerra contra Gènova, que també administrà la ciutat "'t". Sembla, però, que es deixaren de cobrar les imposicions en el moment més àlgid de la crisi; sobretot, la imposició de la quartera desapareix el gener del 1334 fins a finals del $1335^{\prime \prime \prime}$.

Quadre 10. Evolució dels ingressos dels molins (en diners) ${ }^{112}$

\begin{tabular}{|l|c|c|c|c|}
\cline { 2 - 5 } \multicolumn{1}{c|}{} & 1334 & 1335 & 1336 & 1339 \\
\hline & & & & \\
gener & 15034 & 28262 & 39905 & 39228 \\
febrer & 21197 & 27933 & 33607 & 37321 \\
marc & 28679 & 26915 & 31269 & 36315 \\
abril & 48322 & 27849 & 34428 & 46725 \\
maig & 42118 & 30956 & 34900 & 42298 \\
juny & 30330 & 27995 & 36081 & 43609 \\
juliol & 26987 & 23939 & 34101 & 43815 \\
agost & 24090 & 30012 & 34331 & 36659 \\
setembre & 28278 & 31395 & 35937 & 35596 \\
octubre & 34047 & 39026 & 48720 & 42434 \\
novembre & 32039 & 41002 & 41838 & 36373 \\
desembre & 24662 & 36473 & 42632 & 35478 \\
\hline TOTAL & 355783 & 371757 & 447749 & 475851 \\
\hline
\end{tabular}

${ }^{110}$ José Luis MARTín, Contribución de Barcelona a la defensa de Cerdeña (1333-1335), dins Economia y sociedad..., vol.II, pp.259-272.

${ }^{111}$ El juliol del 1334 es tornà a vendre, però fou cancelada (AHCB, Consellers, C-VI-3). A través dels llibres de comptes de la Pia Almoina, sembla que es tornà a cobrar a finals del 1335 (ACB, PA-1335-D).

${ }^{112}$ Són la suma dels ingressos dels casals de Sant Pere, del Soler, del Molins Nous i del molí Carbonell, dels llibres de «les entrades» dels anys 1334 i 1335. En canvi, dels anys 1336 i 1339 no conservem aquest llibre: les hem calculades a partir del llibre de les "sortides», afegint-hi les despeses fixes pagades dels ingressos dels molins. Falten, però, les despeses de manteniment del casal assignades a aquest ingressos que no suposaven grans quantitats. 
Gräfic 6. Evolució del preu del forment i dels ingressos dels molins, 1334-36 i 1339 (núm índex, $100=$ mitjana)

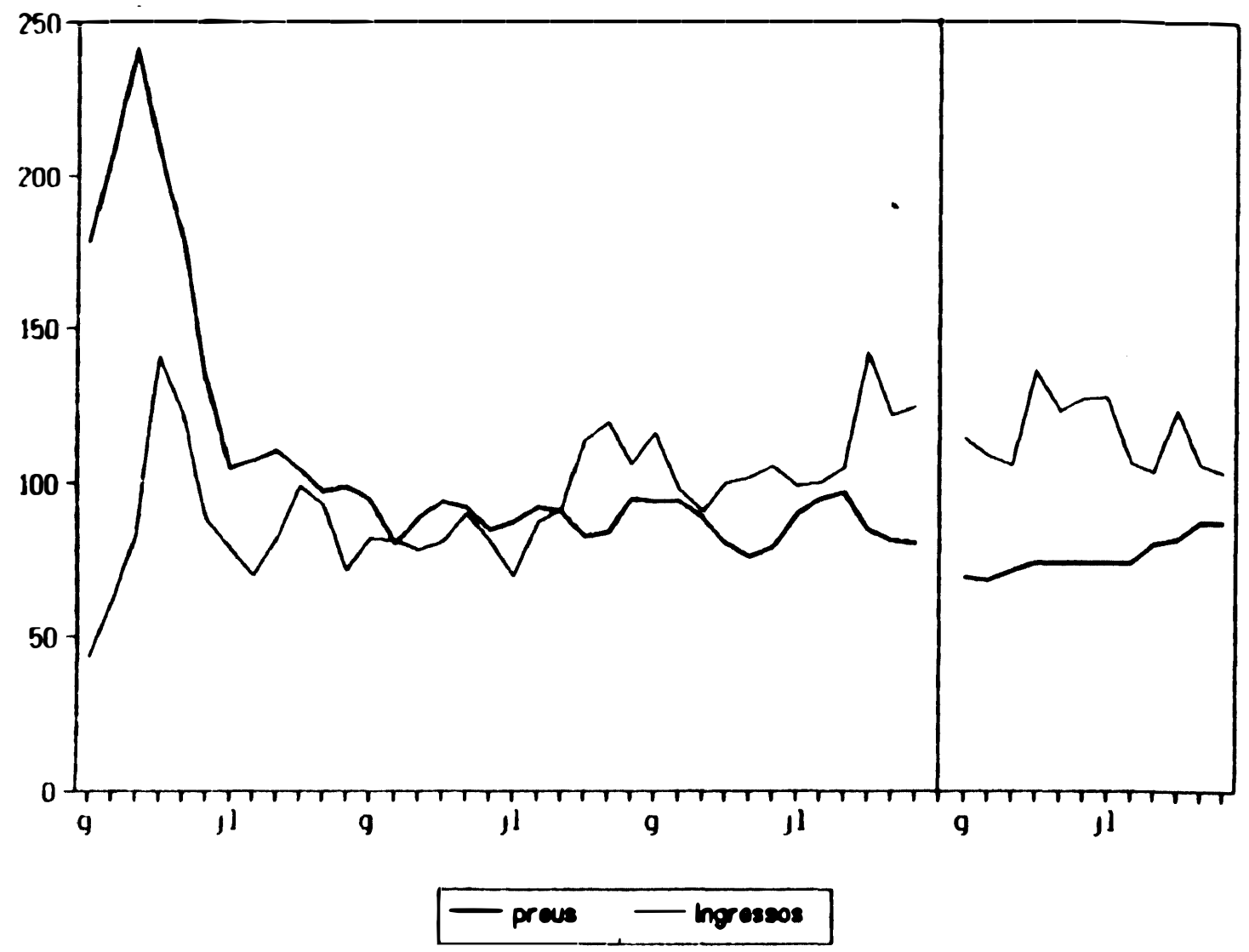

\section{CONCLUSIONS}

A través de les dades que ens ofereixen els llibres de comptes de la Pia Almoina, dels molins reials de Barcelona i del batlle general de Catalunya, hem pogut resseguir els preus del forment des del 1284 al 1345 . Com ja ho hem assenyalat, la carecterística principal d'aquesta evolució és l'alça contínua de preus a partir del 1298 fins al 1334. Malgrat aquesta alça, podriem establir com a preu més normal per al forment a Barcelona els 8 s./q., no tan sols perquè és la mitjana de tota la sèrie sinó també perquè les valoracions que els mateixos coetanis feien s'apropen a aquest valor: per una banda, els dos capbreus de les rendes reials de Catalunya $\left(1315\right.$ i 1327) ${ }^{113}$ valoren els violaris

113 Vegeu notes 8 i 9. 
cobrats sobre el preu diari del forment al voltant dels $8 \mathrm{~s}$./q.; i per l'altra, quan, com ja hem indicat, la Pia Almoina ingressava rendes en espècie, aquestes eren valorades en diners $i$, tot $i$ que varien segons el preu anual, els 8 s./q. n'és el valor més usual.

Gràfic 7. Evolució dels ingressos dels molins (1334-1336, en diners)

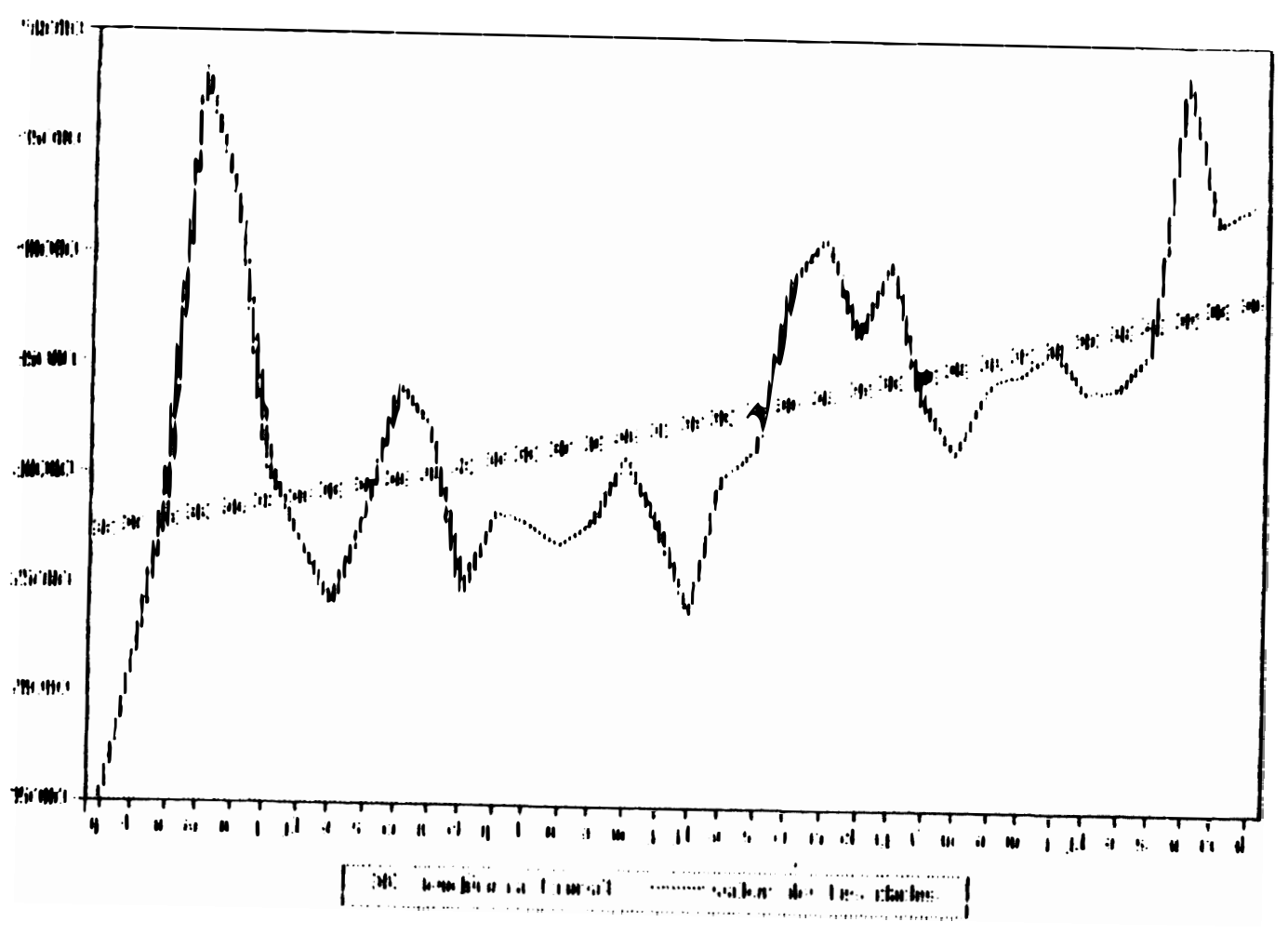


Gràfic 8. Evolució dels preus de la quartera de forment (1334-1336) en diners

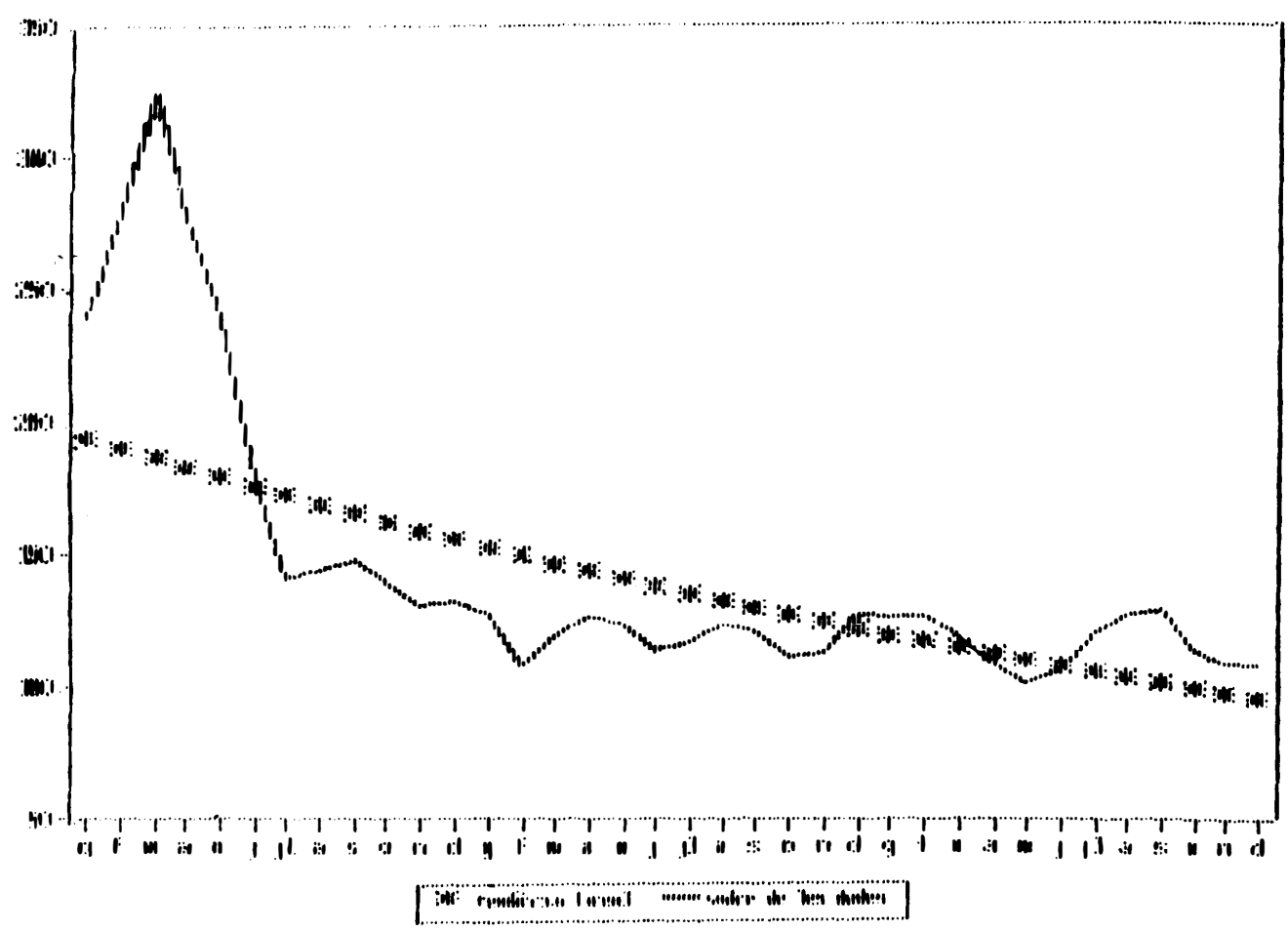

Dins aquesta evolució alcista del preu del forment s'hi poden trobar uns cicles amb unes crisis que coincideixen amb caresties més generals (1284-86, 1291-92, 1302-6, 1308-15, 1325-26, 1333-34) dins l'àmbit de la Mediterrània amb una cronologia diferent de la del nord d'Europa. Això no vol dir que no hi hagués caresties regionals a Catalunya, però Barcelona se'n podia defensar millor per les seves connexions amb els circuits comercials internacionals. Aquestes crisis actuaran de manera més virulenta quan s'ajuntin a les caresties regionals problemes en les importacions motivades preferentment per la guerra, i en una població més dèbil per la pressió fiscal. No és que la guerra sigui la causa de la crisi sinó que debilita els recursos col-lectius (importacions) i individuals (pressió fiscal).

Valorar els efectes de l'alça contínua dels preus del forment i l'impacte de les males anyades a Barcelona no es pot fer només amb l'estudi del forment. Cal estudiar els altres cereals i la resta de productes alimentaris, així com els salaris, i, com hem vist, hi ha fonts a Barcelona per fer-ho. 


\section{RÉSUMÉ}

À travers l'analyse de deux types de livres de comptes barcelonais, très différents l'un de l'autre, l'un émanant de la gestion des moulins royaux et l'autre d'une institution ecclésiastique, celle de Pia Almoina, nous avons pu faire une approche de l'étude du marché de froment à Barcelone pendant le bas Moyen-Age. Tout d'abord nous avons analysé la valeur des mesures utilisées à Barcelona, et, afin de pouvoir évaleur le coût du pain, nous avons réalisé une étude des prix des différents procédés industriels qui permettaient de transformer le froment en pain; nous y avons ajouté l'ensemble des impôts qui grevaient la commercialisation des céréales. A travers l'étude de l'evolution des prix nous avons tenté de réaliser une première approche du comportement du marché barcelonais des céréales au début de la crise qui s'est déclarée pendant le bas Moyen-Age, plus spécialement entre les années 1283 et 1345, opposant ce travail à ceux réalisés à partir de sources qui ne tenaient pas compte des notions de quantité. Pour terminer, nous avons comparé notre étude avec celles réalisées pour la Couronne d'Aragon et la région méditerranéenne, de manière à obtenir une approche toujours plus précise de la chronologie des différentes crises de subsistance.

\section{SUMMARY}

Through the analysis of two quite different series of account books from Barcelona, those coming from the management of royal mills and those redacted by an ecclesiastical institution, the Pia Almoina, we started studying the wheat market in Barcelona during the Middle Ages. We have previously analyzed the value of the measures in Barcelona and, to be able to rate the real price of bread, we have also studied the different industrial processes to make bread out of wheat. Afterwards, we have analyzed the group of taxes that burdened the commercialisation of cereals. Through the study of the evolution of the prices, we have tried to make a first approach of the first stage of the low medieval crisis, more precisely between 1283 and 1345 , taking into account the contrasts with the works already done on the base of sources where the notion of quantity was not considered. Finally, we have compared our results with some studies referring to the crown of Aragon and the mediterranean world, in order to get a more precise idea of the chronology of the subsistence crises. 